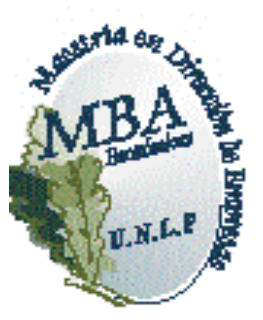

Universidad Nacional de La Plata

Facultad de Ciencias Económicas

MBA - Maestría en Dirección de Empresas

\title{
La gestión de la motivación organizacional con el enfoque de la teoría de Herzberg Un estudio empírico
}

\section{Trabajo final para optar al título de Magister}

\section{La Plata}




\section{Índice}

Resumen__ 1

1. Planteo del Problema __ 2

2. Objetivos de la Investigación___ 2

3. Evaluación del Problema ___ 3

4. Alcance de la Investigación___ 3

5. Marco Teórico de Referencia___ 4

5.1. Antecedentes relacionados con la Investigación____

1. ¿Qué es la motivación?

2. Motivación individual 11

3. Motivación personal — 11

4. La frustración en el trabajo _ 12

5. Necesidades de los empleados__ 14

5.2 Bases Teóricas ___________ 14

Teoría de Maslow 15

Teoría de Alderfer 20

Teoría de Víctor Vroom _ 21

Teoría de Herzberg _ـ 24

Desarrollo de la Teoría de Motivación - Higiene de Herzberg__ 26

Enriquecimiento del puesto 29

Conclusiones del trabajo de Herzberg __ 31

Herzberg Vs. Maslow__ 33

6. Metodología de la Investigación___ 34

Población ___ 34

Tipo de Investigación ___ 35

Técnicas de Recolección de Datos________________ 35

Técnicas de análisis ___ 36

7. Resultados de la Investigación ___ 37

Análisis de Frecuencias __ 37

Análisis de regresión —— 41

8. Conclusiones__ 47

9. Bibliografía_ 50

10. Referencias y Anexos___ 52

Anexo 1: Encuesta de Satisfacción Laboral________ 52

Anexo 2: Gráfico original de los hallazgos de Herzberg ___ 54 


\section{Resumen}

Esta investigación trata sobre la gestión de los factores que inciden en el nivel de satisfacción o insatisfacción en el empleo para una muestra de trabajadores del gran La Plata. En el presente trabajo se toma como referencia la teoría de los factores motivadores e higiénicos de Frederick Herzberg.

El estudio formal de la satisfacción en el trabajo no es tema nuevo, durante décadas se pensó que los factores físicos del ambiente de trabajo eran las principales variables que causaban la satisfacción de los trabajadores.

Años después, los estudios de Elthon Mayo en la Western Electric, en Hawthorne Illinois, revelarían que si bien los factores físicos influían sobre la satisfacción de los trabajadores, los factores sociales tenían una influencian mucho mayor, no sólo en la satisfacción sino también en la productividad.

Casi 30 años después, los hallazgos de Herzberg, advertían que los principales factores que influían en la satisfacción laboral radicaban en factores intrínsecos del trabajo como el sentimiento de logro, el recibir reconocimiento, y el desempeñar un puesto que resultase significativo para el individuo. Estas ideas recibieron una gran aceptación, quizás por su simplicidad, y porque ponían al alcance de los directivos de las empresas y de los gerentes de Recursos Humanos, el diseñar puestos de trabajo que fueran significativos para el trabajador.

Existen varias teorías sobre la motivación del hombre en el trabajo, las cuales plantean distintos factores a tener en cuenta para aumentar la satisfacción laboral. ¿Cuáles son esos factores hoy? El mundo cambió y las necesidades de la gente también han cambiado; por lo tanto las necesidades que los trabajadores van a buscar satisfacer en el trabajo son distintas a las que tenían tiempo atrás.

A través de una investigación empírica, se estudió como es la gestión de los factores motivacionales de Herzberg en los trabajadores del gran La Plata. 


\section{Planteo del Problema}

Existen varias teorías sobre la motivación del hombre en el trabajo, las cuales plantean distintos factores a tener en cuenta para aumentar la satisfacción laboral.

¿Cuáles son esos factores hoy?

Desde la época de Taylor, se empezó a estudiar la motivación, luego aparecen otros autores como Herzberg, Maslow etc., que siguieron profundizando el tema.

El mundo cambió y sigue cambiando día a día desde esos tiempos.

Las necesidades de la gente también han cambiado; por lo tanto las necesidades que los trabajadores van a buscar satisfacer en el trabajo son distintas a las que tenían tiempo atrás. Es por eso que se pregunta:

Los factores que Herzberg plantea en su teoría ¿siguen siendo válidos a pesar de las modificaciones ocurridas en el contexto laboral y personal de los trabajadores del gran La Plata?

\section{Objetivos de la Investigación}

\section{Objetivo General}

Analizar y constatar si aplica la teoría de motivación de Herzberg en los trabajadores del gran La Plata.

\section{Objetivos Específicos:}

- Verificar si se cumple la teoría de Herzberg y en que medida.

- Detectar que factores son más importantes en la motivación en la actualidad.

- Conocer el grado de satisfacción de los trabajadores respecto de su trabajo.

- Describir algunas características respecto de los factores motivacionales relevantes para una gestión motivacional. 


\section{Evaluación del Problema}

El estudio formal de la satisfacción en el trabajo no es algo nuevo, durante décadas se pensó que los factores físicos del ambiente de trabajo eran las principales variables que causaban la satisfacción de los trabajadores, por tal motivo se llevaron a cabo diversos experimentos para medir el efecto de la lluminación, la temperatura y las pausas y descansos en la jornada laboral sobre los niveles de satisfacción de los colaboradores.

Años después, los estudios de Elthon Mayo en la Western Electric, en Hawthorne Illinois, revelarían que si bien los factores físicos influían sobre la satisfacción de los trabajadores, los factores sociales como las relaciones con el jefe o con las del grupo de trabajo, tenían una influencian mucho mayor, no sólo en la satisfacción sino también en la productividad.

Casi 30 años después, los hallazgos de Herzberg, advertían que los principales factores que influían en la satisfacción laboral radicaban en factores intrínsecos del trabajo como el sentimiento de logro, el recibir reconocimiento, y el desempeñar un puesto que resultase significativo para el individuo.

A pesar de que la Teoría de Herzberg, ha sido ampliamente criticada por la metodología que se siguió en los experimentos que dieron origen a ésta, la realidad es que fue un verdadero éxito en su momento histórico de aparición, ya que demostraba que las variables intrínsecas del trabajo tenían un efecto más importante, que las variables físicas, por lo que entre otras cosas resultaba necesario diseñar puestos de trabajo que fueran significativos para el colaborador. Estas ideas recibieron una gran aceptación, quizás por su simplicidad, y porque ponían al alcance de los directivos de las empresas y de los gerentes de Recursos Humanos, el diseñar puestos de trabajo que fueran significativos para el trabajador.

\section{Alcance de la Investigación}

En la presente investigación se analizaron los factores que inciden en la gestión de la motivación laboral de los trabajadores del gran La Plata. según el enfoque de la teoría motivacional de Frederick Herzberg.

Se identifican los factores Higiénicos y Motivacionales y se indagó sobre su vigencia actual.

Para el estudio se tomó una muestra de trabajadores del gran La Plata. 


\section{Marco Teórico de Referencia}

\subsection{Antecedentes relacionados con la Investigación}

A lo largo de la historia se han dado numerosas respuestas al problema de la motivación en el trabajo, si bien es cierto que, desde la Economía de la empresa, no ha sido, hasta épocas recientes cuando ha comenzado a prestársele atención.

Sin embargo para los directivos de las empresas, la motivación representa un problema concreto desde hace tiempo. En la sociedad estadounidense, por ejemplo la atención a los factores motivacionales se ha incrementado durante estos últimos años.

Éste renacido interés se debe a varios factores: una caída de productividad, la necesidad de descubrir formas para motivar y retener a los trabajadores más calificados, de cualquiera de los niveles.

Los cambios demográficos, que han supuesto una mayor diversidad cultural exigen la creación de prácticas motivacionales acorde con las necesidades y valores de los diversos grupos de empleados, de acuerdo con sus costumbres y creencias; pero, sobre todo, han cambiado las expectativas en general.

Algunos de estos elementos parecen característicos de la economía y de la sociedad estadounidense, pero no cabe duda que se vayan extendiendo progresivamente por todo Occidente.

Mucho se ha escrito, en efecto, sobre motivación y dirección de empresas. Se ha escrito tanto que los profesionales de la dirección se encuentran, quizás, desconcertados ante el enorme caudal de sugerencias que se ofrecen y el conflicto que se percibe entre ellas.

Se puede afirmar que la cuestión de la motivación laboral, o motivación en el trabajo, no está aún resuelta.

Por lo tanto, no debe sorprender que las distintas teorías existentes apenas se tengan en cuenta en la práctica directiva. Probablemente el problema no está en las distintas teorías en sí mismas, cuanto en su pretensión implícita de ser universalmente aplicables.

Quizás se deba a que tratan de dar una respuesta universal y única a una cuestión cuyas manifestaciones son siempre muy personales.

No se puede prescindir de las diferencias individuales de las personas que componen una organización, de cualquier tipo que sea. Esas personas tienen experiencias diferentes, aspiran a objetivos diferentes, y están motivadas por necesidades diferentes. En suma, una teoría de la motivación no puede prescindir de considerar que las personas, aunque trabajen juntas y en la misma tarea, son diferentes. 


\section{1. ¿Qué es la motivación?}

En el actuar del individuo dentro de las empresas interactúan tres elementos clave, que de acuerdo con el grado en que se desarrollen cada uno de ellos, conducen al éxito o fracaso de la persona y con eso al de las organizaciones al que pertenecen.

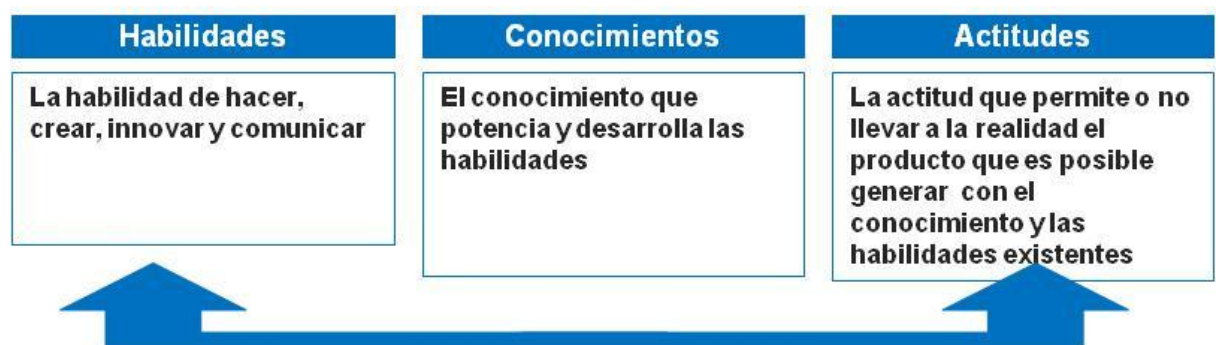

Es elemental señalar que cada quien trabaja en una empresa por diversas razones (salario, arte, mera sobrevivencia u otra), no obstante, existe una razón superior que es el cumplimiento de una misión fundamental del ser humano: servir.

Dado de esta manera, el trabajo de una persona en la empresa no sólo requiere del balance de sus elementos claves, mencionados para ser productivo sino para verter una misión interior que le producen beneficios cualitativos, los cuales afectan directamente a su calidad de vida.

Es conviene resaltar la responsabilidad que tiene la empresa para atender y procurar éste tipo de satisfactores cualitativos como lo son el placer de servir, el sentido de logro y la satisfacción del deber cumplido, sin los cuales el individuo difícilmente puede sentirse a gusto en su trabajo y por lo tanto esperar que sea productivo y que se desarrolle.

Hasta acá se podría decir que la motivación de un individuo tiene que ver con la satisfacción de sus aspectos emocionales, medida de madera cualitativa.

No se puede hablar de calidad de vida en primer término, si no se hace un análisis del individuo y la forma en que ha sido estudiado para resolver después la problemática de su desarrollo.

Se pueden observar algunos aspectos fundamentales que deben estar presentes como medios imprescindibles para lograr la calidad de vida en el individuo, para marcar pautas en su desarrollo y los caminos de superación.

Entonces se puede afirmar que:

La persona debe satisfacer sus necesidades básicas, que no sólo son a nivel emocional y afectivo, sino otra necesidades que se logran a través de dinero, y que conformar lo que se daría en llamar calidad de vida del individuo, factor que jamás debe obviar el empresario, puesto que las consecuencias positivas, si se tiene en cuenta, o negativas, si se da la espalda, recae abruptamente sobre resultados arrojados por la empresa. 
Por lo tanto, "calidad de vida en el trabajo" es una forma diferente de vida dentro de la organización, que buscan desarrollo del trabajador, así como su eficiencia empresarial.

Son beneficios para ambos, los mismos permitirán a la organización orientar sus esfuerzos y recursos que antes utilizaban al enfrentar problemas de los trabajadores, hacia actividades de mayor importancia para el logro de sus objetivos.

Este análisis muestra que una organización que procura la calidad de vida de sus integrantes, está satisfaciendo las necesidades de los mismos, y esto es una forma de mantener los incentivados.

Los principales recursos que se logran a través de implementación de proyecto de calidad de vida de trabajo son:

- Perfeccionamiento e impulso del empleado

- Elevada motivación

- Óptimo desenvolvimiento de sus funciones

- Menor rotación en el empleo

- Bajo porcentaje ausentismo

- Menos quejas

- Períodos de ocio reducidos

- Superior satisfacción en el empleo

- Mayor eficiencia la empresa

Por lo tanto se puede decir que si un empresario está atento a la calidad de vida de sus trabajadores, está generando proceso de motivación en ellos, planteado intuitiva o formalmente.

Frecuentemente se escucha entre los dirigentes de empresas de Argentina la frase "entre mi personal los problemas de motivación están controlados" pero cuando se los contacta directamente a los empleados, la situación existente suele ser otra.

La gente está frecuentemente sometida a grandes presiones entre los objetivos de la empresa y las características de sus colaboradores.

Algo debe quedar claro, que con un grupo desmotivado es muy difícil trabajar, y los resultados finales son infinitamente opuestos al grupo con la moral alta.

La motivación es un motor que se pone en movimiento con estímulo.

Indudablemente la motivación es una respuesta interna, pero desencadenada por factores externos. Implica la disposición del ser humano para actuar en una orientación determinada en un momento determinado.

La motivación del personal hacia los objetivos de la empresa es fundamental para alcanzar el éxito 
Cuando el personal trabaja desmotivado, lo manifiesta de diferentes maneras, una de esas es la falta de deseos de asistir a su lugar de trabajo. En estas condiciones su rendimiento será deficiente, generando él mismo más desmotivación en el grupo. Esto suele convertirse en un círculo vicioso semejante a éste:

Estoy disgusto en el trabajo; llegó tarde

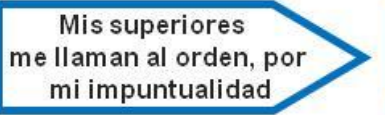

Me predispongo mal, me equivoco en mis tareas

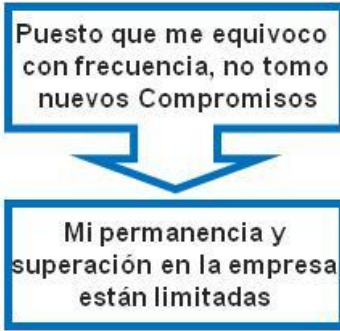

Puesto que me equivoco

con frecuencia, no tomo

nuevos Compromisos

Si no se revierte esta situación, inevitablemente el grupo será afectado y en estas condiciones, ningún directivo alcanzará sus metas.

Es de suma importancia hacerse las siguientes preguntas que hacen referencia a cuatro temas claves de la motivación:

¿Se acostumbra a reunir al personal de la organización para ponerlo al tanto de los acontecimientos que ocurren? Esto es mantener comunicación

¿Se permite la toma decisiones en sus respectivas tareas? Esto es delegar

¿Se elogia cuando logran los resultados deseados por la empresa? Esto es reconocimiento

¿Se reconocen los errores cometidos desde la empresa? Esto es autoevaluarse

MOTIVACION es una modificación positiva de la conducta que ocurre cuando se encuentra un conjunto de razones que justifiquen hacer un esfuerzo para modificar una situación.

Las técnicas de gestión de personal están basadas en una concepción implícita de las relaciones que mantiene la empresa y el empleado.

Hay tres líneas intervinientes, en primer lugar la motivación del personal, la satisfacción y finalmente las implicancias.

La noción de motivación implica siempre la relación empresa-individuo en la que se supone que la empresa es la que, con sus actuaciones y formas de dirigir, puede desarrollar en el individuo la dinámica del trabajo.

La satisfacción representa un estado, está ligado a la productividad y a la eficacia.

Desarrollar la satisfacción del personal mejorando sus condiciones de trabajo, presupone uno de los factores que aportan al eficacia de la empresa. 
Estos dos términos están íntimamente relacionados, la motivación implica un impulso hacía un resultado, mientras que la satisfacción es el resultado ya experimentado.

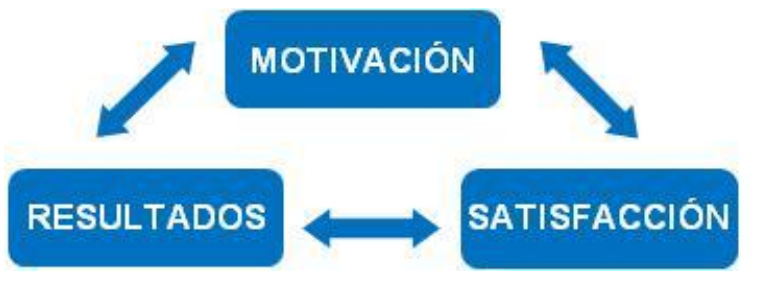

La implicación de las personas es también un factor de eficacia, ya que es la compatibilidad o adecuación entre la persona y el grupo (empresa) en el que trabaja. La relación entre individuo y empresa ya no es unívoca, se da una interacción entre ambos que hace que se cree y se amplíe dicha implicación, empresa-individuo.

La función de la empresa no es construir un sistema que desarrolle la implicación del empleado, sino encontrar un entendimiento y compatibilidad entre los valores de éste y los de la empresa. Un empleado se siente implicado en la medida en que su éxito personal coincide con el de su empresa.

Porter define la implicación como:

- El convencimiento y aceptación de los objetivos y los valores de la organización

- La voluntad de actuar en la dirección de los objetivos y las misiones que la organización ha fijado

- Un fuerte deseo de participar en la vida de la empresa

De todas formas, la implicación de un empleado con la empresa no significa adhesión ni adoración, si no debe suponer una cierta adhesión a los valores de la organización y mayores oportunidades para él mismo.

La empresa no debe "hacer por", sino más bien, "hacer junto con".

En el siguiente cuadro se establece una relación entre cada una de las variables de la primera columna con cada una de las que integran la primera fila: 


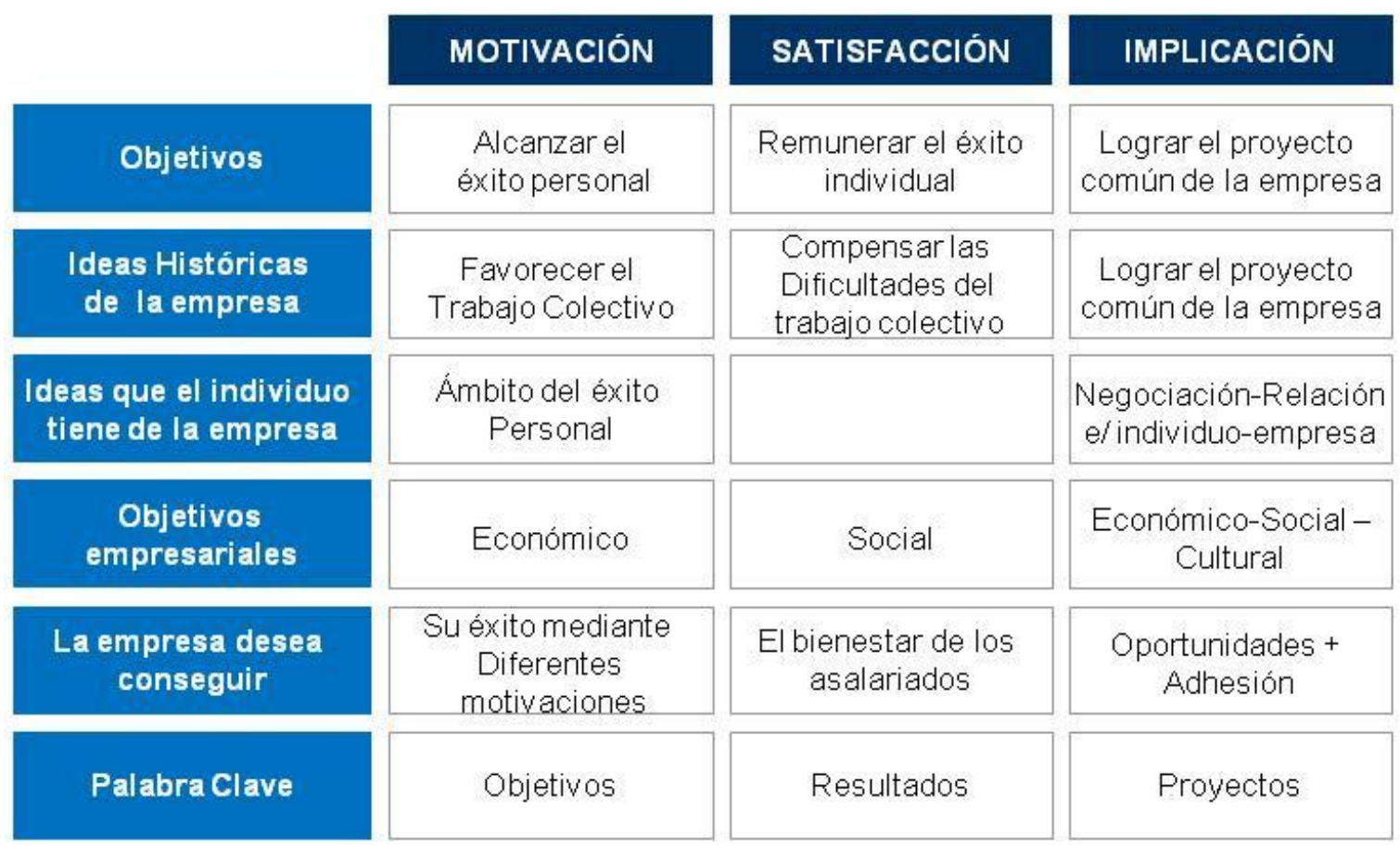

Se puede observar en el cuadro, que sí bien motivación, satisfacción e implicación tienen diferentes acepciones, para el empresario deben conformar un trinomio interrelacionado cuya incorporación y aplicación reportará una dinámica diferente en el desenvolvimiento de la organización.

Las ideas y objetivos de los empleados son parte de la totalidad que conforma la empresa, vale decir que es un todo interrelacionado que no puede desintegrarse sin afectar las partes.

Las consecuencias atribuidas a nivel de satisfacción del trabajador en el contexto organización son:

\section{A. Satisfacción y Productividad}

Una investigación indicó que existe una relación positiva entre la satisfacción y la productividad. Un ejemplo de esto se da en que la relación es más fuerte cuando el comportamiento del empleado no está restringido por los factores externos.

En el caso de los trabajadores que trabajan con máquinas, la productividad va a estar más influenciada por la velocidad de la misma que por su nivel de satisfacción, no obstante existen otros factores motivadores que harán que la relación se cumpla.

Un empleado que se siente complacido con su trabajo y con todas las satisfacciones de diversa índole que el mismo le reporte, estará más compenetrado con la organización y por lo tanto producirá como si lo estuviese haciendo para su total beneficio.

\section{B. Satisfacción y Ausentismo}

El ausentismo provienen de "enfermedades", "problemas familiares", etc. el ausentismo hace que se incurra en mayores gastos médicos, baja de productividad, incremento en costos por personal de reemplazo, etc. 
Múltiples estudios han sugerido que la insatisfacción conduce al ausentismo. El hecho de la falta al trabajo puede representar una forma tentativa y breve de alejarse de él. La causa más frecuente del ausentismo es la baja satisfacción obtenida por la propia realización del trabajo".

Otro factor que causa ausentismo son las actividades ajenas a la empresa que ejercen una atracción mayor que trabajo en sí mismo. Uno puede estar feliz con su trabajo, pero goza más practicando un determinado deporte, y en ocasiones falta.

Un determinado nivel de ausentismo es ciertamente inevitable debido enfermedades, condiciones de clima, problemas de transporte, etc. El punto es determinar cuánto ausentismo es aceptable para la organización. Si bien existe una relación directa entre la satisfacción y el ausentismo, no todo el ausentismo es por causa de la insatisfacción laboral.

\section{Satisfacción y Rotación}

La satisfacción está relacionada negativamente con la rotación. Los costos de la rotación crecen significativamente a medida que los trabajadores son más calificados o de mayor nivel jerárquico.

La rotación demanda mayores gastos de selección de personal y en entrenamiento hasta que la persona alcanza el nivel de competencia requerido. Además, afecta el nivel de productividad y otros aspectos menos obvios, como son las relaciones interpersonales. Si bien existe relación entre satisfacción y rotación no toda la rotación se debe a la insatisfacción laboral.

\section{Satisfacción y Salud de la Empresa}

La relación entre la salud psicológica de la persona y el nivel de satisfacción con el trabajo no ha sido muy bien investigada. Sin embargo se asume que hay una correlación positiva.

Es necesario determinar hasta qué punto la persona satisfecha con su trabajo lo está también con su vida familiar, con sus amigos, etc. Sólo así se podría determinar si la salud mental es una causa o consecuencias de la satisfacción laboral.

Como lo señala Johns (1988), diferentes estudios han demostrado que los trabajadores que describen su trabajo como insatisfactorio tienden a sufrir múltiples síntomas y enfermedades físicas. La asociación entre salud y satisfacción no indica que una sea causa de la otra.

Si bien no existen muchas evidencias que respalde esta postura es necesario tener en cuenta que una persona que se encuentra satisfecha en su trabajo tendrá actitudes más positivas hacia la vida, lo que incluirá el equilibrio de su salud física y psicológica. 


\section{Motivación individual}

La motivación son aquellos factores (impulsos internos y fuerzas externas) capaces de provocar, dirigir y mantener la conducta hacia un objetivo.

Determinar los móviles de la motivación es tan complejo como la naturaleza del ser humano. Si se analizan los propósitos por los cuales una persona trabaja u aporta esfuerzo a una organización, se encontrará que existen muchos factores, desde tener dinero que le permita por lo menos cubrir sus necesidades básicas, hasta aspiraciones superiores como la autorrealización.

Para poder lograr comprender la motivación se debe tener en consideración el aspecto sociocultural de la sociedad donde se desempeña el trabajador y también, la individualidad de éste.

Ocurre que lo que una persona considera recompensa importante, para otra persona podría ser algo inútil. Porque los seres humanos difieren enormemente en el concepto y la forma de percibir las oportunidades de lograr éxito en el trabajo.

\section{Motivación personal}

Los programas motivacionales se enfrentan con la dificultad de que generalmente descuidan algo fundamental: identificar aquéllos factores que realmente motivan a la persona de manera individual y colectivamente.

Todos los seres humanos tienen necesidades e intereses completamente distintos, y también diferente grado y forma de satisfacción de los mismos.

Por ejemplo, el significado del dinero es totalmente diferente para cada uno. Quizá para algunos es un medio importante para lograr fines, para otros no tiene relevancia alguna, para otros es un recurso, otros consideran que es un fin en sí mismos, para otros es el mayor motivador. Por consiguiente, proyectar motivar al personal para mejorar la productividad sin considerar su individualidad, es una falacia.

La administración del factor humano es una tarea un tanto compleja. Cada persona es un fenómeno sujeto a influencia de muchas variables y entre esas las diferencias en lo que se refiere a aptitudes y patrones de comportamientos son muy disímiles.

Además, considerando la individualidad de las personas, cada uno valora o conceptualiza a su manera las circunstancias que lo rodea, así como emprender acciones sobre la base de sus intereses particulares.

En la empresa quizá se observa que muchas personas tienen puntos en común, pero también tienen eso que las hace únicas, sus individualidades. Estas diferencias se deben, sin duda, a las diferentes maneras que el entorno ha influido en ellas. 
Puede darse el caso de trabajadores aptos, de buen nivel intelectual, de aptitudes especiales, de conocimientos en la tarea o el oficio, pero que sin embargo no tienen el rendimiento eficiente que se espera.

Suele ser difícil de reconocer que las metas de los empleados no estén alineadas, o formen parte de las metas de la organización.

- Por un lado, los trabajadores tratan de sacar mejores beneficios de la empresa sin que su contribución sea importante.

- Por otro lado, muchos empresarios explotan a sus trabajadores para obtener mejores utilidades.

- Esta relación compleja debe hacer que el empresario tome conciencia de los siguientes aspectos, que casi son principios en la administración de personal:

- Un individuo hará algo de algo, y personalmente siente que ese algo es importante para él.

- Un individuo hará más de algo, sin personalmente siente que ese algo es también importante para otros a quienes considerar importantes para él

- Un individuo hará algo más si personalmente siente que progresa por hacer ese algo

\section{La frustración en el trabajo}

Cuando un empleado actúa para conseguir un objetivo y encuentra alguna barrera obstáculo que le impide lograrlo, se produce la frustración, que lleva a la persona a ciertas reacciones, tales como:

- Desorganización de comportamiento (conducta y lógica explicación aparente).

- Agresividad (física, verbal y psicológica).

- Reacciones emocionales (ansiedad, Aflicción, nerviosismo y otras manifestaciones como insomnio, problema circulatorio, digestivo, etcétera física, verbal y psicológica).

- Alineación, apatía y desgano.

Es frecuente encontrar a trabajadores "rendidos", con la moral baja que se reúnen con sus compañeros para quejarse, en algunos casos, conspiran contra la empresa u optan por conductas incorrectas, como forma de reaccionar ante la frustración.

¿Qué ocurre con la desmotivación?

La organización que no motiva efectivamente sus empleados obtiene de los mismos: 
- Pasividad en sus ocupaciones

- Sabotaje de ideas y hechos

- Retaceo en los esfuerzos

- Deserción de la empresa

- Robo de información

- Falta de orgullo

- Altercados

- Improductividad

De todos estos factores devienen las pérdidas de beneficios para la empresa y para sus empleados, se convierte en un círculo vicioso.

\section{Reconocer el desempeño}

La mirada confortadora del supervisor, la autonomía operativa, el perfeccionamiento, el reconocimiento a la labor bien efectuada, la equidad en el tratamiento de los temas que los afligen, el cumplimiento de las promesas, los beneficios, etc., ofician de impulsores para que las personas busquen incesantemente superar sus estándares de rendimiento, disfrutar la tarea y desarrollar así su máximo potencial.

Los diferente relevamientos realizados a empresas de gran envergadura, a pymes, o de tipo familiar demuestran que la motivación utilizando como medio el reconocimiento y la recompensa requiere un equilibrio en diseño, y equidad en la administración.

En general, se entiende por recompensa aquello que está ligado a lo económico, y al reconocimiento, se lo relaciona con la parte emocional, tal como cumplimiento de promesas, confianza, lealtad, aceptación de ideas, etc.

Depende de lo que se premie, será lo que se genere en otras organizaciones.

Si se premia a todos por igual, sin sentido y en forma invariable, el personal se acostumbra y dejará de ser un motivante.

Si se instaura una política de recompensa monetaria, se estarán generando escenarios, que cuando se les solicite algo demás preguntarán cuanto le van a pagar, o dado que el crecimiento es finito, irán de empresa en empresa, o lo que es peor se quedarán pero transformados en los más caros y lo menos conformes.

Si se estimula a los empleados solo desde el punto de vista emocional como resultado se conseguirán personas simplemente agradecidas.

El asunto está en contra el equilibrio entre la recompensa de reconocimiento 


\section{Motivación como propulsor de la productividad}

Otra de las herramientas efectivas y eficaces para motivar al personal y obtener la productividad deseada, es mediante el enriquecimiento del puesto. Se trata de la partición vertical de los puestos.

Un puesto enriquecido organiza las ocupaciones a fin de que el trabajador pueda realizar una actividad completa, mejorar su libertad e independencia, aumenta su responsabilidad y aporta retroalimentación, de manera tal que un individuo puede valorar y corregir su propio desempeño.

\section{Necesidades de los empleados}

¿Cuáles son las motivaciones esenciales que tienen los trabajadores para realizar tareas con eficiencia?

La necesidad de alcanzar un logro: se da cuando las personas sienten que pueden hacer algo y que eso los hace sentir bien, así que continúan haciéndolo para mejorar cada vez más.

- Contar con desafíos adecuados

- Deseo vehemente de aprender: cuando los empleados aman su trabajo desean aprender más y ser mejores en este.

- Contar con oportunidades de aprendizaje

- Anhelo de contribuir: cuando los empleados conocen el valor de lo que hacen el de sus aportes, entonces tratan de optimizar su trabajo.

- Desarrollar trabajos de importancia

\subsection{Bases Teóricas}

Principales Teorías desarrolladas sobre Motivación en el trabajo.

A continuación se desarrollarán los fundamentos teóricos de los autores como Maslow, Herzberg, Alderfer, Mc Clelland, y la teoría de Vroon. Profundizando especialmente la teoría de motivación de Frederick Herzberg, siendo esta la más relevante para esta tesis.

Primero se comenzara por los primeros teóricos de las necesidades. 


\section{Teoría de Maslow}

\section{¿Que necesitan las personas?}

Una de las preguntas básicas y eternas que se hacen los psicólogos es: ¿Por qué las personas hacen lo que hacen?

Más precisamente, ¿Cuáles son los motivos que inducen la conducta de las personas?

Maslow elaboró una teoría muy completa sobre las motivaciones de las personas. Esta teoría va ligada a su teoría de la personalidad.

Maslow fue muy optimista en cuanto a la naturaleza de las personas y afirma que todos los seres humanos tienen una naturaleza buena. Pero ésta naturaleza está marcada por una serie de necesidades que hay que satisfacer si una persona tiene satisfechas las necesidades, entonces estará sana y feliz. Por tanto, aquello que motiva a la persona es la búsqueda del equilibrio entre la necesidad y su satisfacción.

Las personas poseen dos tipos de necesidades:

Las necesidades de carencia

- Necesidades fisiológicas: comer, beber, dormir, relaciones sexuales...

- Necesidades de estimación y aceptación

- Necesidades de valoración

- Necesidades de protección y seguridad

- Las necesidades de crecimiento son las propias de la autorrealización.

Maslow asevera que estas necesidades están establecidas de forma jerárquica, es decir que las primeras se han de satisfacer antes que el resto. El establecimiento de necesidades implica una teoría dinámica de las motivaciones en las personas.

Esto quiere decir que una persona no se queda parada cuando ha satisfecho una necesidad, sino que inmediatamente desea satisfacer las necesidades siguientes y así sucesivamente.

Delante de las teorías equilibrio u homeostasis, Maslow defiende la teoría del desarrollo, de tal manera que el hombre nunca se manifiesta satisfecho del todo, y siempre quiere ir más allá. Esta teoría culmina con las necesidades de crecimiento, que no tienen límite. 
Las necesidades de carencia son propias de toda especie humana y, en algunos aspectos, también de los animales. Satisfacer las necesidades de carencia permite evitar la enfermedad física y psíquica.

\section{NECESIDADES DE AUTOREALIZACION}

Satisfacer las necesidades de crecimiento permite la autorrealización con total plenitud.

Jerarquía de necesidades humanas y algunos de sus satisfactores relacionados con el puesto.

Maslow no considera las motivaciones del individuo como impulsos sino que las necesidades superiores son activas cuando se satisfacen las inferiores.

\section{Necesidades Fisiológicas:}

Desde el comienzo da una vida hasta su muerte lo que le ocurre al hombre es que en cuanto satisface una necesidad otra automáticamente ocupa ese lugar, este proceso es interminable y constante.

Las necesidades del hombre están organizadas en una jerarquía de importancia. En el nivel más bajo, aunque de fundamental importancia cuando no se las atiende, están las necesidades fisiológicas. A menos que las circunstancias sean insólitas, sus necesidades de amor, de status, de reconocimiento, no operan si tiene algún tiempo el estomago vació. Pero cuando se come regularmente, el hambre deja de ser una motivación importante. Sucede lo mismo con las demás necesidades fisiológicas del hombre: de abrigo, de descanso, de ejercicio, de refugio.

\section{Necesidades de Protección o Seguridad:}

Se habla de la necesidad de estar protegido contra el peligro, las amenazas, las carencias. Implica tanto el daño físico como el emocional. Si el hombre se siente amenazado o dependiente su necesidad mayor es de garantías, de protección, de defensa. 
Cuando un empleado está en situación de dependencia, las necesidades de protección pueden llegar a cobrar considerable importancia. Actos arbitrarios por parte de la administración, una conducta que provoque incertidumbre con respecto a la pertenencia en el empleo o que refleje favoritismo o discriminación, una administración impredecible de la política organizacional.

En el ámbito laboral estas necesidades se traducen a un deseo de estabilidad laboral, seguro médico familiar, seguridad económica, pensión de jubilación, etc.

\section{Necesidades Sociales}

Cuando están satisfechas las necesidades fisiológicas del hombre y no siente temores con respecto a su bienestar físico, sus necesidades sociales se constituyen en motivadores importantes de su conducta: Necesidades de pertenecer, de asociación, de ser aceptado por los demás, de dar y recibir amistad y amor.

Las empresas saben de estas necesidades, pero suponen que puede ser una amenaza para la organización.

Esta estudiado y demostrado que el trabajo en equipo, con un grupo unido y en condiciones adecuadas es mucho más eficaz que el trabajo individual de cada uno de ellos por separado.

Muchas veces las empresas se enfocan a controlar y dirigir al hombre, destruyendo esta tendencia grupal ya que teme la hostilidad del grupo hacia sus objetivos.

El hombre tiende a perjudicar los objetivos de la organización cuando se frustran de esa manera sus necesidades sociales (y tal vez también las de protección).

Se vuelve negativo, antagónico, no coopera. Pero este comportamiento es una consecuencia y no una causa.

Es por eso que para satisfacer estas necesidades se recomienda en la organización generar actividades sociales, culturales, deportivas, círculos de calidad, trabajo en equipo etc. Orientados a que los trabajadores tengan la oportunidad de ejercitar esta necesidad. Estimular los grupos informales proactivos es una buena decisión. Una muestra de la manifestación de esta necesidad son los matrimonios que se dan entre hombres y mujeres de una empresa, situación que pone en evidencia que al trabajador, además de cumplir con sus obligaciones, le importa el aspecto social.

\section{Necesidades de estima}

Por encima de las necesidades sociales, están las necesidades del yo, estas son las de mayor significación para la administración empresarial y para el hombre mismo. Estas necesidades se dividen en dos tipos:

- Las vinculadas con la autoestima: de confianza en sí mismo, de independencia, de realización, de competencia, de conocimiento.

- Las necesidades con la propia reputación: de status, de reconocimiento, de aprecio. 
A diferencia de las anteriores, esta rara vez se satisfacen: el hombre busca inagotablemente una mayor satisfacción de estas necesidades una vez que se vuelven primordiales para él.

\section{Necesidades de Autorrealización:}

Se constituyen en una especie de coronación de las necesidades del hombre. Se trata de la necesidad de desarrollar el potencial propio, de autodesarrollo continuado, de ser creativo en el sentido más amplio de este término.

Es evidente que las condiciones de vida actual ofrecen insuficientes oportunidades para la expresión de estas necesidades relativamente débiles. La insatisfacción que admitan la mayoría de las personas con respecto a otras necesidades de nivel inferior desvían sus energías hacia la lucha para satisfacerlas y las de autorrealización permanecen latentes.

Maslow indica que estos niveles son interdependientes, se superponen porque cada nivel superior se presenta antes de que el inferior quede completamente satisfecho. En la sociedad las personas suelen estar parcialmente satisfechas en cada una de las áreas de necesidades. Pero la mayor parte de los individuos suelen obtener mayor satisfacción de las necesidades inferiores que de las superiores.

Supuestos de la Teoría de Maslow

- Cuando una necesidad de nivel inferior está satisfecha o correctamente atendida, nace el comportamiento conducente a querer satisfacer otras necesidades del nivel inmediatamente más elevado. En otros términos, cuando se satisface una necesidad del nivel más bajo, deja de ser motivadora del comportamiento, lo cual induce a que la necesidad de un nivel más elevado sea atendida, convirtiéndose en un factor motivacional.

- No todas las personas consiguen llegar a la cima de la pirámide. Algunas personas gracias a las oportunidades de la vida, buscan y se inquietan por las necesidades de autorrealización; otras se detienen en las necesidades de estima; y otros en las necesidades sociales. Mientras que otros se queden preocupados exclusivamente por las necesidades de seguridad y fisiológicas, sin que consigan satisfacerlas por completo.

- Cuando las necesidades de nivel inferior están razonablemente satisfechas, las necesidades de niveles más elevados comienzan a dominar la conducta. Sin embargo cuando no se satisface alguna necesidad, ésta vuelve a predominar en el comportamiento, generando tensión en el organismo. La necesidad más apremiante o más importante monopoliza al individuo y tiende, de manera automática, a organizar la movilización de las diversas facultades del organismo para atenderla. 
- Cada individuo posee más de una motivación. Todos los niveles actúan conjuntamente en el organismo, pero las necesidades más elevadas predominan sobre las más bajas si éstas han sido suficientemente satisfechas o atendidas. Toda necesidad está íntimamente relacionada con el estado de satisfacción o de insatisfacción de otras necesidades. Su consecuencia sobre el organismo es siempre global y de conjunto, jamás aislada.

- Cualquier comportamiento motivado es como un canal, mediante el cual numerosas necesidades pueden ser expresadas o satisfechas conjuntamente.

- Ante un obstáculo para satisfacer una necesidad surge la frustración, convirtiéndose en una amenaza psicológica. Estas amenazas ocasionan las reacciones generales de emergencia en el comportamiento humano. Maslow postula que la motivación para satisfacer las necesidades de tipo superior sólo aparece y es operativa cuando están satisfechas las necesidades de nivel inferior. Así por ejemplo, una persona estará motivada para buscar la satisfacción de las necesidades de seguridad cuando tienen razonablemente satisfechas las fisiológicas, del mismo modo buscara satisfacer las necesidades de autorrealización cuando tenga satisfechas las cuatro anteriores.

Maslow representa al hombre medio de la siguiente manera:

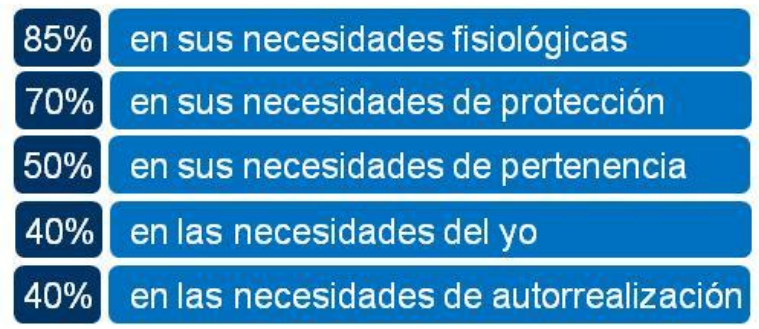

Los porcentajes de satisfacción muestran que a la hora de cubrir las necesidades de la persona se tienen en cuenta fundamentalmente lo que Herzberg llamo factores higiénicos, y que precisamente son los que vuelven a cero; esto es importante para rever en que se está invirtiendo en las empresas para motivar, quizás se están produciendo gastos que no reporten resultados positivos, sino por el contrario, pueden generar efectos negativos. 


\section{Teoría de Alderfer}

Replanteo la teoría de Maslow

Clayton Alderfer llevó a cabo una revisión de la teoría de las necesidades de Maslow, la cual se convirtió en su teoría ERG, existencia, relación y crecimiento. Este autor agrupo las necesidades humanas en tres categorías mencionadas.

- Existencia: satisface las exigencias materiales básicas, entre ellas las necesidades fisiológicas y de seguridad.

- Relación: deseos sociales y de status exigen interacción con otras personas para ser satisfechas, corresponden a las necesidades de amor y al componente extremo de la estima. En esta instancia se puede hablar del sentido de pertenencia que necesita desarrollar la persona.

- Crecimiento: deseo intrínseco de alcanzar desarrollo personal, equivaldría al componente intrínseco de la estima de Maslow y la autorrealización

Alderfer plantea las siguientes ideas:

- En contraste con la rígida pirámide de Maslow, Alderfer propone que un individuo puede estar en cualquiera de los grupos de necesidades 0 eventualmente en los tres al mismo tiempo.

- Si se reprime la satisfacción de una necesidad de orden superior, aumenta el deseo de satisfacer una de orden inferior. Por ejemplo, la imposibilidad de satisfacer necesidades de relación tiende a incrementar necesidades de existencia, como mejores condiciones de trabajo, dinero, etc., así la frustración puede llevar a la regresión a una necesidad de nivel inferior.

- Las necesidades de crecimiento son ilimitadas y cobran fuerza cada vez que se satisfacen.

Esta teoría toma en cuenta las diferencias individuales con respecto a las necesidades de las personas.

Variables como la educación, los antecedentes familiares y el ambiente cultural pueden alterar la importancia do la fuerza impulsora que posee un grupo de necesidades para un individuo determinado. 


\section{Teoría de Víctor Vroom}

¿Cómo influyen las expectativas individuales?

Vroom propone que la motivación es producto de la valencia o el valor que el individuo pone en los posibles resultados de sus acciones y la expectativa de que sus metas se cumplan. La importancia de esta teoría es la insistencia que hace en la individualidad y la variabilidad de las fuerzas motivadoras, a diferencia de las generalizaciones implícitas en las teorías de Maslow y Herzberg.

Para motivar a las personas no es suficiente con ofrecerles algo para satisfacer sus necesidades importantes. Para que se sientan realmente motivadas deberán estar razonablemente convencidos de que tienen la capacidad para obtener la recompensa. Por ejemplo, decir a una persona que se la nombrará gerente de ventas en su zona probablemente no lo motivará si sabe que es casi imposible.

Víctor Vroon desarrollo su teoría sobre la motivación tomando en cuenta las expectativas de éxito de las personas. Afirma que la fuerza de una tendencia a actuar de una manera determinada depende de la fuerza de la expectativa de que el acto este seguido de un resultado determinado y de lo atractivo de que ese resultado sea para el individuo.

En un sentido más práctico un empleado se siente motivado a realizar un alto nivel de esfuerzos cuando cree que ese esfuerzo llevará a una buena evaluación de desempeño, una buena evaluación redundará en recompensas organizacionales, como bonificaciones, incremento de salario $o$ un ascenso; y las recompensas satisfarán las metas personales del empleado.

Según este autor la motivación es un producto entre dos variables:

\section{VALENCIA * EXPECTATIVA $=$ FUERZA}

- Valencia: es la anticipación de los resultados de una acción.

- Expectativa: es la probabilidad de que ocurra el resultado deseado.

- Fuerza: representa la intensidad de la motivación de la persona.

La teoría de Vroon está dentro de la línea aceptada actualmente por los psicólogos y sociólogos contemporáneos.

Para Vroon el nivel de productividad individual depende de tres fuerzas básicas que operan dentro del individuo:

- Los objetivos individuales, o sea, la fuerza de deseo de lograr objetivos

- La relación percibida entre productividad y el alcance de los objetivos individuales

- La capacidad del individuo para influir su propio nivel de productividad, en la medida en que él crea que puede influenciarlo. 
Para Vroon, un individuo puede desear aumentar la productividad cuando se imponen tres condiciones:

Los objetivos personales del individuo. Que pueden incluir dinero, seguridad en el cargo, aceptación social, reconocimiento y trabajo interesante. Existen otras combinaciones de objetivos que una persona puede tratar de satisfacer simultáneamente.

La relación percibida entre satisfacción de los objetivos y la alta productividad. Si un trabajador tiene como un importante objetivo el tener un salario mayor y si trabaja con la base en la remuneración por producción, podrá tener una fuerte motivación para producir más. Sin embargo, si su necesidad de aceptación social por los otros miembros del grupo es más importante, podrá producir por debajo del nivel que el grupo considero como patrón de producción informal. Producir más podrá significar el rechazo del grupo.

La percepción de su capacidad de influir su productividad. Si un empleado cree que un gran volumen de esfuerzo gastado tiene poco efecto sobre el resultado, tendera a no esforzarse mucho, como es el caso de una persona colocada en un cargo sin entrenamiento adecuado o de un trabajador colocado en una línea de montaje de velocidad fija.

Según Vroon, esos tres factores determinan la motivación del individuo para producir en determinado tiempo.

Esta teoría también es llamada Modelo Circunstancial de Motivación por que resalta las diferencias entre las personas y entre sus cargos.

La teoría de Vroon es una teoría de motivación y no de comportamiento.

La motivación ocurrirá si suceden dos cosas:

- Si el valor del resultado particular (como llegar a ser gerente de ventas) es muy elevado para la persona.

- Si la persona siente que tiene oportunidades razonablemente buenas para lograr el trabajo y obtener el resultado.

Esta teoría enfoca tres clases de relaciones:

Relación esfuerzo - Desempeño: La probabilidad que percibe la persona de que realizar el esfuerzo llevara a un determinado desempeño.

Relación desempeño - Recompensa: el grado en que una persona siente que desempeñarse en un determinado nivel los conducirá al logro de un resultado.

Relación recompensa - Metas personales: el grado hasta el cual las recompensas organizacionales satisfacen las metas o necesidades personales de un individuo y lo atractivas que son para esas personas. 
Las tres clases de relaciones que traducen en preguntas que los empleados necesitan responder afirmativamente para maximizar su motivación.

- ¿Si rindo un máximo esfuerzo, se reconocerá en mi evaluación de desempeño?

- ¿Si obtengo una buena evaluación de desempeño, dará lugar a recompensas organizacionales?

- ¿Si soy recompensado, son atractivas las recompensas para mis intereses personales?

La clave de esta teoría, es la comprensión de las metas del individuo y los vínculos existentes entre el esfuerzo y el desempeño, entre el desempeño y la recompensa y, entre la recompensa y la satisfacción de las metas individuales.

Reconoce también que no hay un principio universal que explique la motivación de todas las personas. Las organizaciones realmente deberían recompensar a los individuos por su desempeño en lugar de hacerlo con criterio tales como, la antigüedad, el esfuerzo, el nivel de habilidades, y la dificultad del puesto. En aquellas organizaciones donde esto no sucede, se encuentra que un gran segmento de la fuerza de trabajo realiza bajos niveles de esfuerzo para desempeñar su puesto.

\section{Clases de relaciones propuestas}
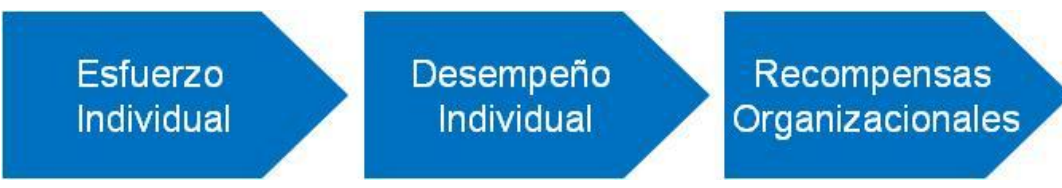

\section{Metas \\ Personales}

1. Relación esfuerzo - Desempeño

2. Relación desempeño - Recompensa

3. Relación recompensa-Metas personales 


\section{Teoría de Herzberg}

Frederick Irving Herzberg, una de las más destacadas figuras de la psicología industrial y organizacional y padre de las mundialmente conocidas teorías de los dos factores de la motivación y del enriquecimiento del trabajo, falleció el 19 de enero de 2000 en el University Hospital de Salt Lake City, a la edad de 76 años.

\section{Introducción:}

A mediados de los años cincuenta, luego de un breve período en el Servicio de Ayuda Psicológica de Pittsburgh -una firma consultora sin fines de lucro-, ingresó a la Sección de Investigaciones y Proyectos del Servicio Estadounidense de Salud Pública. Seis años más tarde, en 1956, se incorpora a la Case Western Reserve University como director del Departamento de Psicología. Durante su estadía en esta Universidad le cupo iniciar y dirigir un fecundo programa de investigaciones sobre salud mental en la industria.

El problema que captaba la atención de Herzberg era que, tanto en el campo de la salud física como psicológica, a la fecha se disponía de un amplio conocimiento en relación con las causas por las cuales las personas enfermaban, pero muy poco se sabía respecto de lo que hacía que la gente se conservara sana.

Uno de los principales hallazgos de dicho programa de investigación le permitió a Herzberg establecer la idea eje, en función de la cual habrían de girar todos sus aportes al conocimiento de las causas de la motivación y satisfacción laboral. De acuerdo con Herzberg, la enfermedad mental y la salud mental no actúan como dos aspectos contrapuestos de un mismo continuum, como tradicionalmente se había venido sosteniendo, sino que, por el contrario, lo hacen en planos diferentes, como el dolor y el placer. No por el hecho de eliminarse las fuentes de sufrimiento en las personas se produce automáticamente placer, simplemente se vuelven las cosas a un punto neutro. El placer es el resultado de otros factores. De la misma manera, en el medio laboral, no por eliminarse las fuentes de insatisfacción en los empleados necesariamente éstos experimentan satisfacción absoluta en el trabajo que realizan.

Dos años más tarde, en 1959, publicó Motivación at Works, un informe de sus propias investigaciones y las de sus colaboradores acerca de la salud mental en la industria y en el cual expuso formalmente su conocida Teoría de Motivación- Higiene.

En esencia, la teoría se originó en la investigación que Herzberg y sus colaboradores realizaron en un grupo de ingenieros y contadores a quienes se les pidió respondieran a las siguientes preguntas: "Recuerde usted algún momento en que se haya sentido excepcionalmente bien respecto de su trabajo, ya sea en su empleo actual o en algún otro que haya tenido. Dígame que ocurrió" y, "Recuerde usted algún momento en que se haya sentido excepcionalmente mal respecto a su trabajo, ya sea en su empleo actual o en algún otro que haya tenido. Dígame que ocurrió". 
El análisis de las respuestas obtenidas permitió a Herzberg y a sus colaboradores concluir que la motivación en los ambientes laborales se deriva de dos conjuntos de factores independientes y específicos. Los primeros, asociados con los sentimientos negativos $o$ de insatisfacción que los empleados aseguraban experimentar en sus trabajos y que atribuían al contexto de sus puestos de trabajo. Herzberg denominó a estos factores de higiene, porque actuaban de manera análoga a los principios de la higiene médica: eliminando o previniendo los peligros a la salud. Los factores de higiene abarcan aspectos tales como la supervisión, las relaciones interpersonales, las condiciones físicas del trabajo, las remuneraciones, las prestaciones, la seguridad en el trabajo, y las políticas y prácticas administrativas de la empresa, entre otros. De acuerdo con Herzberg, cuando dichos factores no están presentes 0 se aplican incorrectamente no permiten que el empleado logre satisfacción. Sin embargo, cuando están presentes no originan en los empleados una fuerte motivación sino que sólo contribuyen a disminuir o a eliminar la insatisfacción.

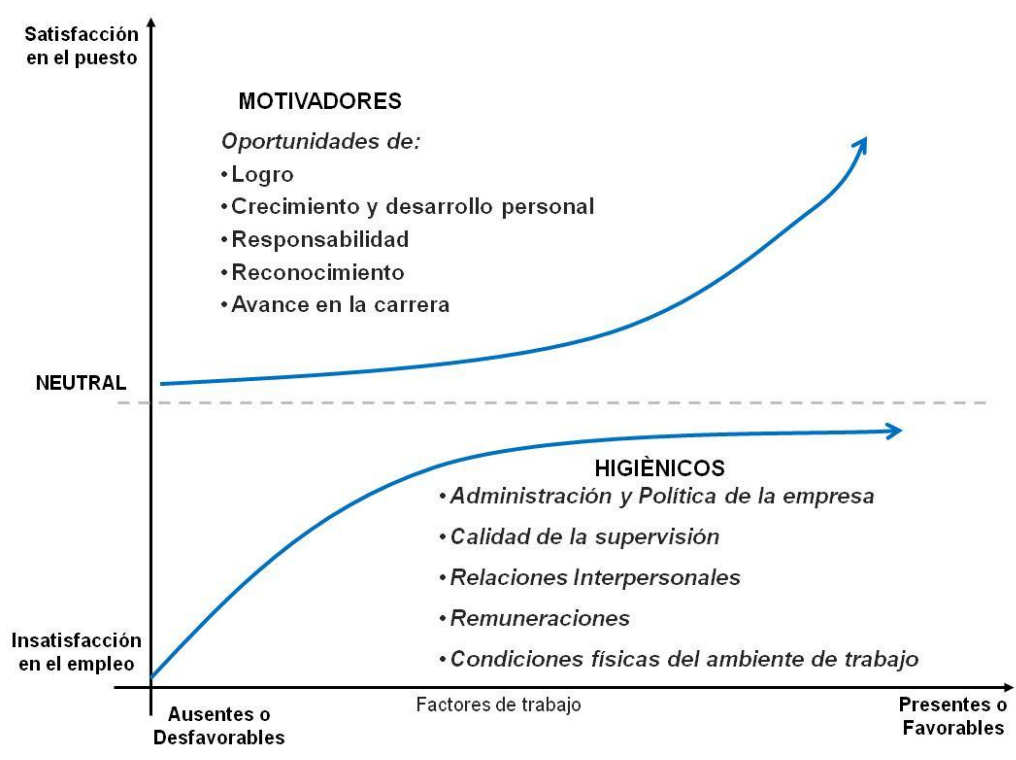

El segundo conjunto de factores se asociaba con las experiencias satisfactorias que los empleados experimentaban y que tendían a atribuir al contenido de sus puestos de trabajo. Herzberg denominó a este tipo de factores motivadores. Entre éstos se incluyen aspectos tales como la sensación de realización personal que se obtiene en el puesto de trabajo, el reconocimiento al desempeño, lo interesante y trascendente de la tarea que se realiza, la mayor responsabilidad de que se es objeto por parte de la gerencia, y las oportunidades de avance profesional y de crecimiento personal que se obtienen en el trabajo, entre otros. Herzberg sostuvo que, si estos factores están presentes en el puesto de trabajo contribuyen a provocar en el empleado un elevado nivel de motivación, estimulándolo así a un desempeño superior.

Este hallazgo le permitió a Herzberg establecer uno de los principios más importante en el campo de la motivación laboral: la satisfacción y la insatisfacción son conceptos distintos e independientes. Cuando mucho, los factores de higiene no producen satisfacción alguna y pueden generar insatisfacción. Por el contrario, los motivadores dan origen a satisfacciones y, en el peor de los casos, no crean insatisfacción. La figura 1 gráfica este importante principio. 
Herzberg presenta al mundo empresarial dos revolucionarias ideas:

- La primera de ellas, que, siendo la satisfacción y la insatisfacción laboral dos dimensiones distintas e independientes, las estrategias motivacionales que se habían venido empleando, tales como mejorar las relaciones humanas, aumentar los incentivos salariales, y establecer condiciones adecuadas de trabajo, eran incorrectas; tales elementos no generan una mayor motivación, cuando mucho sólo actúan previniendo o eliminando la insatisfacción.

- La segunda idea fue sostener que el solo aumento de los salarios, sin que la gerencia se preocupara de las condiciones en que se realizan las tareas, no sirve para motivar. De acuerdo con Herzberg, en la medida en que el dinero se convierte en un factor estándar en el trabajo, pierde inmediatamente su capacidad motivadora, pudiendo engendrar una peligrosa semilla entre los empleados: incentivarlos a abrigar más altas expectativas respecto del período venidero de reajustes salariales.

\section{Desarrollo de la Teoría de Motivación - Higiene de Herzberg}

"Si tienen a alguien en un trabajo, utilícelo pronto, si no puede utilizarlo, deshágase de él, ya sea mediante la automatización o seleccionando a alguien con menos habilidad. Si usted no puede utilizarlo, o no puede deshacerse de él, tendrá un problema de motivación". Herzberg

\section{¿Qué satisface a las personas?}

Son dos fenómenos diferentes Satisfacción e Insatisfacción, que también deberán ser originados por factores diversos y tener sus dinámicas propias.

Esta experiencia fue llevada acabó formulando dos preguntas:

$$
\text { ¿Qué experiencias le producían satisfacción? }
$$

\section{¿Qué experiencia le producían insatisfacción?}

Descubrió que los factores que provocaban satisfacción estaban directamente relacionados con lo que uno hace, es decir, con el contenido del trabajo, por el contrario lo que provocaba descontento estaban en relación directa con el medio del cual se desarrollaba su trabajo, a estos Herzberg los llamo factores higiénicos.

Lo que hace que las personas se sientan felices está relacionado con el tiempo de trabajo o tareas que se le asignen, y lo que los hace sentir descontentos es la forma en que se los trata.

La dinámica del hombre se concentra en la exhibición de su talento y la única forma de lograrlo es mediante la ejecución de tareas y responsabilidades que le permitan desarrollar todo su potencial. 
Las satisfacciones están más relacionadas con los factores motivacionales y por ende tienen efecto a mediano y largo plazo. Los factores higiénicos, en cambio, están más relacionados con los factores estimulantes por lo que sus efectos son de muy corto plazo.

Por ejemplo, el tiempo durante el cual uno se siente satisfecho con lo que gana es lo suficientemente limitado como para qué en el término de dos semanas desaparezcan los efectos del aumento.

Para Herzberg la motivación de las personas depende de los factores que se explican a continuación:

\section{Factores higiénicos:}

Son las circunstancias que rodean a las personas cuando trabajan; involucran las condiciones físicas y ambientales de trabajo, la mensualidad, los beneficios sociales, las políticas de la empresa, el tipo de supervisión recibida, el clima de las relaciones entre las directivas y los empleados, los reglamentos internos, las oportunidades existentes, etc.

Corresponden a la perspectiva ambiental y constituyen los factores que las empresas han utilizado habitualmente para lograr la motivación del personal.

Sin embargo, los factores higiénicos poseen una capacidad muy limitada para influir en la conducta los trabajadores.

La expresión "higiene" refleja con exactitud su carácter preventivo y profiláctico, y muestra que sólo se destinan a evitar fuentes de insatisfacción en el ambiente como amenazas potenciales que

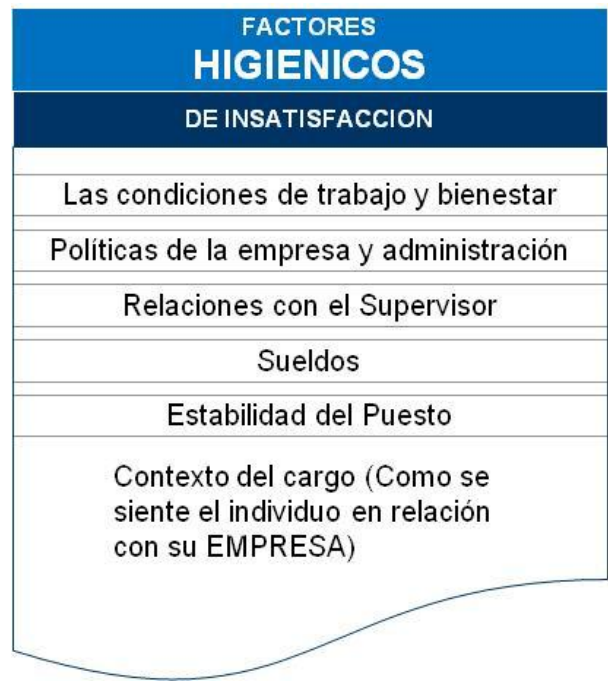
puedan romper su equilibrio.

Cuando estos factores son óptimos, simplemente evitan la insatisfacción, puesto que su influencia en el comportamiento no logra elevar la satisfacción de manera sustancial y duradera.

Cuando son precarios, producen insatisfacción y se denominan entonces factores de insatisfacción. 
Ellos encierran:

- Condiciones de trabajo y bienestar

- Políticas de la compañía y la administración

- Relaciones con el supervisor

- Competencias técnicas de supervisor

- Sueldos

- Estabilidad en el puesto

- Relaciones con los colegas o compañeros

Los factores higiénicos constituyen el contexto del cargo. Se tiene que tener en cuenta que siempre vuelven a cero.

Por ejemplo, no cuentan las veces que se le haya manifestado al empleado lo expeditivo que es para la realización de tareas, si es que no se lo repite constantemente.

Ejemplo práctico

$Y$ un empleado recibe un aumento de $\$ 1.000$ y al año siguiente se le otorga nuevamente otro aumento, pero de $\$ 500$, psicológicamente para esa persona el efecto será que le han ocasionado una reducción de $\$ 500$.

Consecuentemente esto debe llevar a la reflexión al empresario en lo que respecta a la puesta en marcha de herramientas de motivación, que si tienen en cuenta solamente esto factores, se puede correr el riesgo, en caso de no equilibrarla con los factores motivacionales, de caer a corto plazo en la desmotivación, desinterés y descontento de los empleados.

\section{Factores motivacionales}

Tienen que ver con el contenido del cargo, las tareas y los deberes relacionados con el cargo en sí, produce un resultado de satisfacción perdurable y un aumento de la productividad muy por encima de los niveles corrientes.

El termino motivación encierra sentimientos de la realización, de evolución, y de reconocimiento profesional, manifiestos en la ejecución de tareas

Ideales que constituyen un gran desafío y tienen bastante trascendencia para el trabajo.

Cuando los factores motivacionales son óptimos, elevan la satisfacción de modo sustancial, cuando son precarios, provocan la pérdida de satisfacción se denominan factores de satisfacción y se relacionan con el contenido de cargo en sí e incluyen:

\begin{tabular}{|c|}
\hline $\begin{array}{c}\text { FACTORES } \\
\text { MOTIVACIONALES }\end{array}$ \\
\hline DE SATISFACCION \\
\hline El trabajo en si mismo \\
\hline El reconocimiento \\
\hline La Responsabilidad \\
\hline El progreso personal \\
\hline El progreso personal \\
\hline $\begin{array}{l}\text { Contenido del cargo (Como se } \\
\text { siente él individuo en relación } \\
\text { con su CARGO. }\end{array}$ \\
\hline
\end{tabular}


- Delegación de la responsabilidad

- Autonomía de decidir cómo ejecutar el trabajo

- Ascensos

- Utilización plena de las habilidades personales

- Formulación de objetivos y evaluación relacionado con estos

- Simplificación de cargo (por quien lo desempeña)

- Ampliación o enriquecimiento del cargo (horizontal o vertical)

Los factores motivadores tienen un efecto duradero que no vuelve a cero.

Por ejemplo, alguien que escribe un libro se recupera intelectualmente, ese efecto motivador perdurará de por vida y aunque nunca más escriba un libro, no volverá a su estado anterior.

Si se ofrece a los empleados programas de capacitación, formulados como planes a desarrollarse al mediano y largo plazo, se los estará haciendo partícipes de logros cuyo efecto motivador perdurará en ellos.

Cuando una persona logra algo superándose, el logro no desaparece.

\section{Enriquecimiento del puesto}

Cuando se hace referencia al enriquecimiento del cargo, Herzberg propone la sustitución de las tareas más simples y elementales del cargo por tareas más compleja, que ofrezcan condiciones de desafió y satisfacción personal, que alimenten el crecimiento profesional.

El enriquecimiento de la tarea trae efectos altamente deseables, como el aumento de

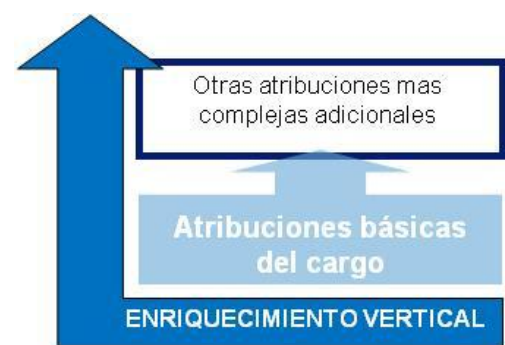
motivación y de productividad, reduce la ausencia en el trabajo, y la rotación de personal.

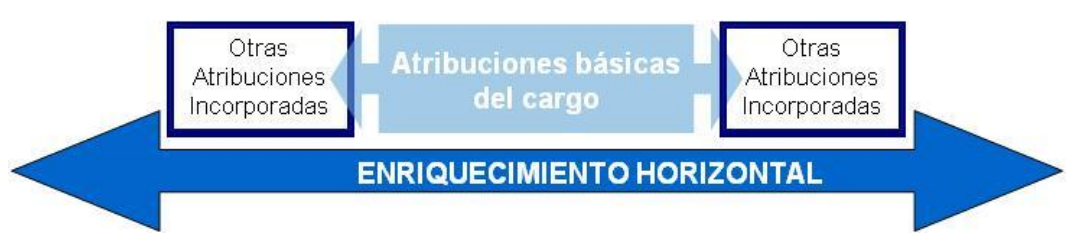

Claro que no todos estuvieron de acuerdo con este sistema, según los críticos, notan una serie de efectos indeseables, como el aumento de ansiedad, aumento de del conflicto entre las expectativas personales y los resultados de su trabajo en las nuevas tareas enriquecidas; sentimiento de explotación cuando la empresa no acompaña lo bueno de las tareas con el aumento de la remuneración; reducción de las relaciones interpersonales, dado a las tareas dadas.

\section{EFECTOS DESEABLES}

- Aumento de la motivación

-Aumento de la productividad

-Reducción del ausentismo.

-Reducción de la rotación del

$\overline{\mathrm{Pab}}$
EFECTOS INDESEABLES

-Aumento de la ansiedad

-Aumento del conflicto

- Sentimiento de explotación

-Reducción de las relaciones

personales. 
Por lo tanto referirse a enriquecimiento del cargo exige llenar el puesto de trabajo de factores motivadores, de tal manera que el empleado encuentre en éste la oportunidad de satisfacer sus necesidades de crecimiento personal.

En este sentido, de acuerdo con Herzberg, los gerentes más que motivar los empleados cargándoles sus trabajos verticalmente con tareas rutinarias -por ejemplo, dándole al individuo algo más que hacer- deben, por el contrario, cargar horizontalmente los trabajos proporcionándolas mayores posibilidades de encontrar oportunidades de logro, reconocimiento al desempeño, tareas estimulantes, ser objeto de mayores responsabilidades, experimentar crecimiento personal y de progreso laboral y, sobre todo, permitiéndoles ejercer control sobre los diferentes recursos que le permitan llevar a cabo sus trabajos. Según Herzberg, sólo la carga vertical del trabajo hace posible su enriquecimiento.

\section{Estrategias para el enriquecimiento del trabajo}

Herzberg recomendó a los gerentes siete estrategias básicas para el enriquecimiento de los puestos de trabajo, a continuación se presenta un resumen de ellas.

\section{PRINCIPIOS DE CARGA VERTICAL}

\section{ESTRATEGIAS}

Suprimir algunos controles mientras se conserva la obligación de rendir cuentas.

Incrementar la rendición de cuentas de los individuos a cerca de su propio trabajo.

Proporcionar a cada persona una unidad natural de trabajo, completa (módulo, división, área, etc.)

Garantizar autoridad adicional a un empleado en su actividad, libertad de trabajo.

Elaborar informes periódicos sobre la calidad del desempeño y ponerlos directamente a disposición de los empleados, más que del supervisor.

Introducir nuevas y más difíciles tareas no manejadas previamente.

Asignar a los individuos tareas específicas 0 especializadas que le permitan convertirse en expertos

\section{MOTIVADORES IMPLICADOS}

Responsabilidad y Logro personal

Responsabilidad y Reconocimiento

Responsabilidad, Logro y Reconocimiento

Responsabilidad, Logro y Reconocimiento

Reconocimiento Interno

Crecimiento y Aprendizaje

Responsabilidad, Crecimiento y ascenso

Aunque Herzberg reconoció que sus estrategias motivacionales no eran un asunto fácil de implementar en el medio organizacional, enfatizó la necesidad de que los gerentes hicieran de ellas una política continua en sus empresas.

En las últimas décadas, las pruebas aportadas por diferentes investigadores (Hackman y Oldham, 1976) han venido reconociendo que en la práctica del enriquecimiento del trabajo se encuentra la respuesta definitiva a la motivación de los empleados, señalándose que la clave de ello radica fundamentalmente en la habilidad de los administradores para establecer un ajuste "casi" perfecto entre las características y 
requerimientos del puesto de trabajo y las capacidades, habilidades y necesidades de crecimiento del individuo.

\section{Conclusiones del trabajo de Herzberg}

La satisfacción en el puesto es función de contenido o de las actividades desafiantes y alentadoras del cargo: "contenidos del cargo", como se siente la persona en relación a su cargo; estos son los llamados factores motivadores.

La insatisfacción en el cargo es función del ambiente, de la supervisión, de los colegas y el contexto general del cargo: "contexto del cargo", como se siente la persona en relación con su empresa; son los llamados factores higiénicos.

Herzberg llegó a la conclusión de que los factores responsables de la satisfacción profesional están desligados y son distintos de los factores responsables de la insatisfacción profesional: "el inverso a la satisfacción profesional, no es la insatisfacción, es no tener satisfacción profesional alguna; de la misma manera, lo opuesto a la insatisfacción profesional es carácter de insatisfacción profesional y no la satisfacción".

En cuanto a los factores higiénicos, para que exista una mayor dosis de motivación en el cargo, Herzberg propone como herramienta de motivación el "enriquecimiento de la tarea", que consiste en aumentar deliberadamente la responsabilidad, los objetivos y el desafío de las tareas del cargo (desarrollado con anterioridad en motivación como propulsor de productividad).

Las satisfacciones están más relacionadas con los factores motivacionales y, por ende tienen efecto a mediano y largo plazo, en cambio, los factores higiénicos están más relacionados con los factores estimulantes por lo que sus efectos son de muy corto plazo.

Por ejemplo, el tiempo durante cual uno se siente satisfecho con lo que gana es lo suficientemente limitado como para qué en el término de dos semanas desaparezcan los efectos del aumento.

El rol del factor dinero. Este es un factor netamente higiénico, aunque por estar asociado a muchas acciones de motivación, a veces se incluye erróneamente dentro de estas.

Tómese el ejemplo de un ascenso en una empresa. Constituye factor motivador, y como generalmente va acompañado de un aumento de sueldo, deberá ser considerado como factor higiénico, por las razones expuestas con anterioridad.

El dinero, en general, como factor estimulante e insume gastos cada vez mayores y efectos estimulantes cada vez menores.

Se considera importante destacar que la recompensa o el premio económico es lo que se obtiene por hacer algo que habitualmente no se haría a no ser por el premio que 
representa. En cambio, la motivación consiste en que el hombre piense: "hago esto porque para mí tiene valor hacerlo".

Éste es el capital más preciado que tiene el empresario, el deseo natural de las personas de realizarse en su trabajo. Sin embargo, se observa en muchas empresas, grandes dificultades o limitaciones para implementar acciones que conllevan a una relación más armónica entre las personas y la factibilidad del cumplimiento de sus aspiraciones de realización personal.

Se considera, sin duda, que el sufrimiento en una persona es muy evidente, sin embargo su deseo de realización no es tan destacable a simple vista, es necesario descubrirlo. Siempre es más fácil administrar aspectos relativos a la higiene.

Se requiere mucho talento y preparación para dirigir a la gente de acuerdo con sus aptitudes, y desde ese punto de vista, se considera que los gerentes encargados de ello deben estar preparados para el logro de este objetivo.

En la mayoría de las empresas falta y si existe no se aprovecha, la imaginación, pues sólo se preocupan en saber si sus empleados cumplen su función, el lugar de averiguar si también tienen aptitudes creativas.

En las organizaciones en donde se fomenta y propicia consciente y continuamente la creatividad, donde el clima libera más que inhibe la creatividad, están notoriamente presentes las condiciones que aseguran la renovación y el progreso continuo.

La creatividad, un atributo tan inestimable en los buenos tiempos, es obligatorio en épocas de cambio rápido y presenta la única opción viable al estancamiento y el fracaso.

Los factores son los que fundamentalmente determinan la conducta en el trabajo: uno es el talento que posee, y otro en lo que se le permite hacer, o sea el grado de libertad para aplicar su iniciativa personal, su creatividad.

Según él, la mejor manera de motivar a alguien es estructurando su puesto en forma tal que la persona experimente una sensación de logro al realizar su trabajo.

Eso se logra ya que se apela a las necesidades de nivel superior de los empleados para obtener el logro y aumentar la autoestima. Se trata de necesidades que nunca quedan enteramente satisfechas, por eso, la mejor manera de motivar a los empleados es crear desafíos y oportunidades de logro mejor en sus puestos.

Herzberg concluye su teoría de la motivación-higiene diciendo:

"Posiblemente debamos abandonar la esperanza de obtener una sociedad más sana por medio de la higiene. La única manera de desarrollar una sociedad saludable es dando más satisfacción a la gente y no menos insatisfacciones" 


\section{Herzberg Vs. Maslow}

En cierta medida, las conclusiones de Herzberg coinciden con la teoría de Maslow, en que los niveles más bajos de necesidades humanas tienen relativamente poco efecto en la motivación cuando el patrón de vida es elevado.

Herzberg dividió a las necesidades del hombre en dos niveles: inferior (fisiológico, seguridad, social) y uno superior (ego, autorrealización) y afirma que la mejor manera de motivar a alguien es ofrecer la satisfacción de las necesidades superiores.

Como se indica en la figura, los satisfactores e insatisfactores identificados por Herzberg se asemejan a los factores propuestos por Maslow.

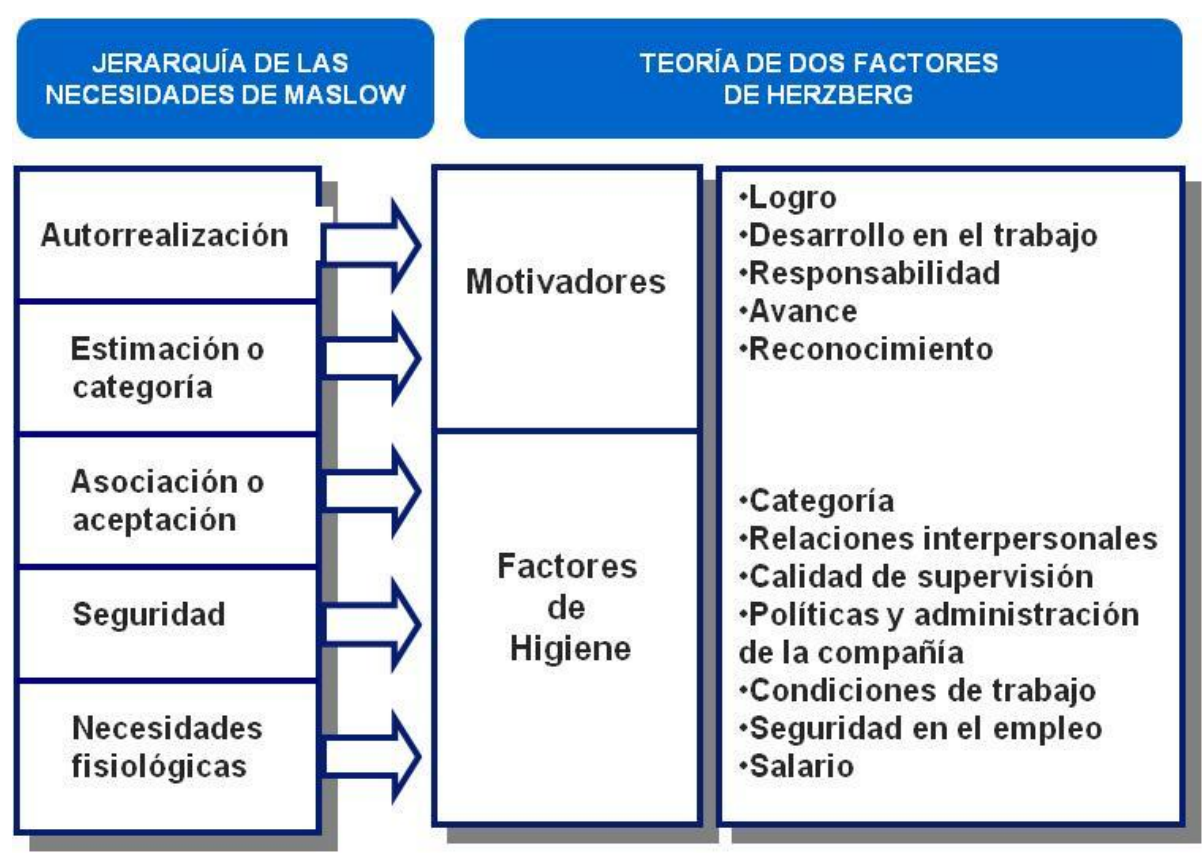




\section{Metodología de la Investigación}

\section{Población}

Área de Investigación:

El área consensuada para el siguiente trabajo abarcó a los trabajadores que residen y/o trabajaban en la zona geográfica del gran La Plata (Berisso, Ensenada)

Universo:

Para fines del estudio, el universo considerado fue de 248.224 trabajadores activos, con título universitario ${ }^{1}$.

Recopilación de datos

Respecto de la fuente de información, se trabajó con datos primarios obtenidos mediante encuestas directas.

Plan de muestreo

Para seleccionar la muestra se recurrió a un muestreo aleatorio, seleccionando aquellas personas de fácil acceso pertenecientes a diferentes empresas, universidades y contactos. El muestreo fue probabilístico, dado que las muestras fueron seleccionadas al azar.

- Unidad de muestreo:

Persona mayor de 25 años, argentina con título universitario, sin hacer discriminación de la carrera; que viva en la ciudad de La Plata y que se encuentre actualmente trabajando.

- Tamaño de la Muestra:

Para el cálculo del tamaño de la muestra se utilizó la fórmula para
poblaciones infinitas.
$n=\frac{\left(Z^{2}{ }^{*} p^{*} q\right)}{E^{2}}$

- Error máximo aceptable: $9,65 \%$

- Porcentajes estimado de la muestra: $50 \%$

- Nivel de confianza: $95 \%$

Tamaño de la muestra: 104

\footnotetext{
${ }^{1}$ Fuente: Censo Nacional de Población y Viviendas 2001 - Elaboración: Dirección Provincial de Estadísticas
} 


\section{Tipo de Investigación}

El tipo de investigación que se llevó a cabo fue de tipo empírico cuyo objetivo es aportar nuevas ideas en función del conocimiento de la realidad.

El estudio realizado es del tipo descriptivo, con el fin evaluar la vigencia de la teoría de Herzberg. Es una descripción de campo porque se basa en información y datos primarios obtenidos directamente de la realidad y es descriptiva porque se buscó desarrollar una imagen, una fiel representación del fenómeno estudiado a partir de las características de la situación actual respecto de la motivación, de los trabajadores del gran La Plata.

También abarca la faz explicativa, toda vez que se han determinado las variables que explican apropiadamente la Satisfacción General.

\section{Técnicas de Recolección de Datos}

\section{El Cuestionario}

El cuestionario utilizado fue elaborado a partir del instrumento original de Herzberg, el cual ha sido diseñado para fundamentar su teoría de los dos factores y también fueron considerados otros cuestionarios de satisfacción laboral ${ }^{2}$.

Cada ítem plantea una situación referida al trabajo actual, los entrevistados indicaron que grado de satisfacción le genera el aspecto del trabajo en cuestión.

Las respuestas para cada ítem fueron medidas a través de la siguiente escala de satisfacción.

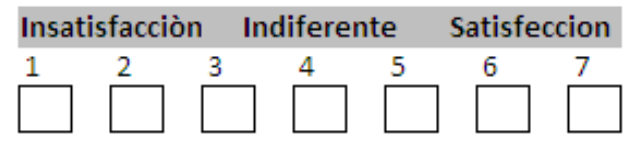

Los valores 1, 2 y 3 indican, en algún grado, insatisfacción; los valores 5, 6, y 7 indican un cierto grado de satisfacción. El valor 4 refiere a indiferencia del aspecto preguntado del trabajo para generar satisfacción o insatisfacción.

Para la medición de la satisfacción general con su puesto se utilizó la siguiente escala.

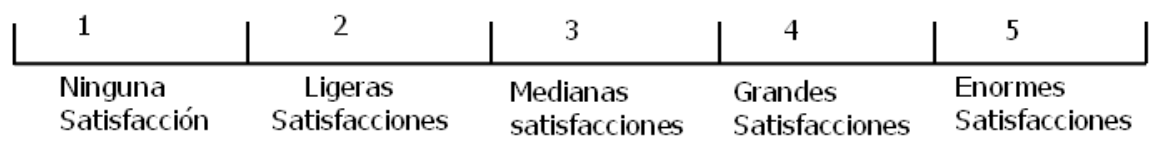

En el anexo 1 se encuentra el modelo de cuestionario utilizado.

\footnotetext{
${ }^{2}$ Cuestionario de satisfacción laboral S4/82 J.L.Melia y J.M. Peiro (1998); Cuestionario de satisfacción labroal S21/26 Pradilla;Cuestionario de Font Roja ;Cuestionario NPT213 Validado por el Survey Reserch Center, de Michigan;Otros cuestionarios de Marti, N; Sancerni, M.D; Oliver, A. y Tomás, J.M.
} 
Cada uno de los factores de Herzberg fue evaluado mediante dos o tres situaciones tendientes a medir de forma más real y representativa cada factor.

\begin{tabular}{l}
\hline REMUNERACION \\
\hline Que el sueldo sea acorde al trabajo que realizas. \\
\hline Que el sueldo básico sea el del convenio. \\
\hline El dinero que recibo como premiose incentivos.
\end{tabular}

De esta manera se evitó preguntar de forma directa si, por ejemplo, la remuneración le genera satisfacción o insatisfacción, la respuesta a esta pregunta directa puede tener causas muy diversas.

\section{Técnicas de análisis}

La información que se obtuvo de los cuestionarios aplicados, se trabajó con el Statistical Package for the Social Sciences en su versión SPSS 15.0. y con MS Excel 2007.

Se realizaron análisis univariado, de frecuencias, regresiones y correlaciones. 


\section{Resultados de la Investigación}

\section{Análisis de Frecuencias}

La muestra encuestada de 104 trabajadores, arrojó el siguiente resultado.

A continuación se presentan las tablas de frecuencia agrupadas por factores motivacionales e Higiénicos.

\begin{tabular}{|c|c|c|c|c|c|c|}
\hline ANALISIS DE FRECUENCIAS Y PORCENTAJES DE & \multicolumn{3}{|c|}{ Frecuencia } & \multicolumn{3}{|c|}{ Porcentaje } \\
\hline Escala de valoración & $5-6-7$ & 4 & $1-2-3$ & $5-6-7$ & 4 & $1-2-3$ \\
\hline PREGUNTAS Y FACTORES MOTIVACIONALES & 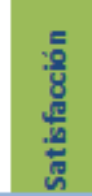 & 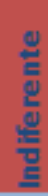 & 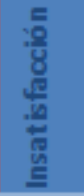 & 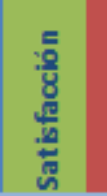 & 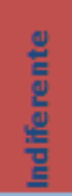 & 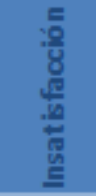 \\
\hline Desarrollo, logro y Realización & \multicolumn{3}{|c|}{ Frecuencia } & \multicolumn{3}{|c|}{ Porcentaje } \\
\hline $\begin{array}{l}\text { Tener la posibilidad de que en el trabajo, te dejen hacer las cosas en } \\
\text { las que mas te destacas y te gustan. }\end{array}$ & 99 & 1 & 4 & $95 \%$ & $1 \%$ & $4 \%$ \\
\hline $\begin{array}{l}\text { Que las tareas de tu puesto de trabajo sean acordes a tus } \\
\text { capacidades y tu personalidad. }\end{array}$ & 92 & 1 & 11 & $88 \%$ & $1 \%$ & $11 \%$ \\
\hline Reconocimientos & \multicolumn{3}{|c|}{ Frecuencia } & \multicolumn{3}{|c|}{ Porcentaje } \\
\hline Que tu jefe te reconozca los trabajos bien hechos & 97 & 3 & 4 & $93 \%$ & $3 \%$ & $4 \%$ \\
\hline Que tu jefe preste atención a la calidad de tu trabajo & 86 & 3 & 15 & $83 \%$ & $3 \%$ & $14 \%$ \\
\hline El trabajo en si & \multicolumn{3}{|c|}{ Frecuencia } & \multicolumn{3}{|c|}{ Porcentaje } \\
\hline El tipo de tareas y actividades de tu puesto de trabajo & 95 & 8 & 1 & $91 \%$ & $8 \%$ & $1 \%$ \\
\hline Que te den la libertad para realizar y organizar el trabajo a tu & 98 & 6 & 0 & $94 \%$ & $6 \%$ & $0 \%$ \\
\hline Que tu puesto cuente con tareas variadas, creativas y desafiantes & 102 & 2 & 0 & $98 \%$ & $2 \%$ & $0 \%$ \\
\hline Responsabilidad & \multicolumn{3}{|c|}{ Frecuencia } & \multicolumn{3}{|c|}{ Porcentaje } \\
\hline Que tu trabajo tenga cierta responsabilidad & 94 & 4 & 6 & $90 \%$ & $4 \%$ & $6 \%$ \\
\hline Que tengas participación en las decisiones de mi depto. & 90 & 10 & 4 & $87 \%$ & $10 \%$ & $4 \%$ \\
\hline Que el trabajo que realizo sea importante & 104 & 0 & 0 & $100 \%$ & $0 \%$ & $0 \%$ \\
\hline Promoción y Ascenso & \multicolumn{3}{|c|}{ Frecuencia } & \multicolumn{3}{|c|}{ Porcentaje } \\
\hline Que en el trabajo me den formación. & 99 & 1 & 4 & $95 \%$ & $1 \%$ & $4 \%$ \\
\hline Que existan Oportunidades de promoción y ascenso & 99 & 1 & 4 & $95 \%$ & $1 \%$ & $4 \%$ \\
\hline
\end{tabular}

En el cuadro 1 se puede observar que los primeros 12 motivos generadores de satisfacción según Herzberg fueron puntualizados en general por los trabajadores de la región, con los valores más altos de la escala 5-6 y 7 en su mayoría, afirmando la importancia de estos en la motivación.

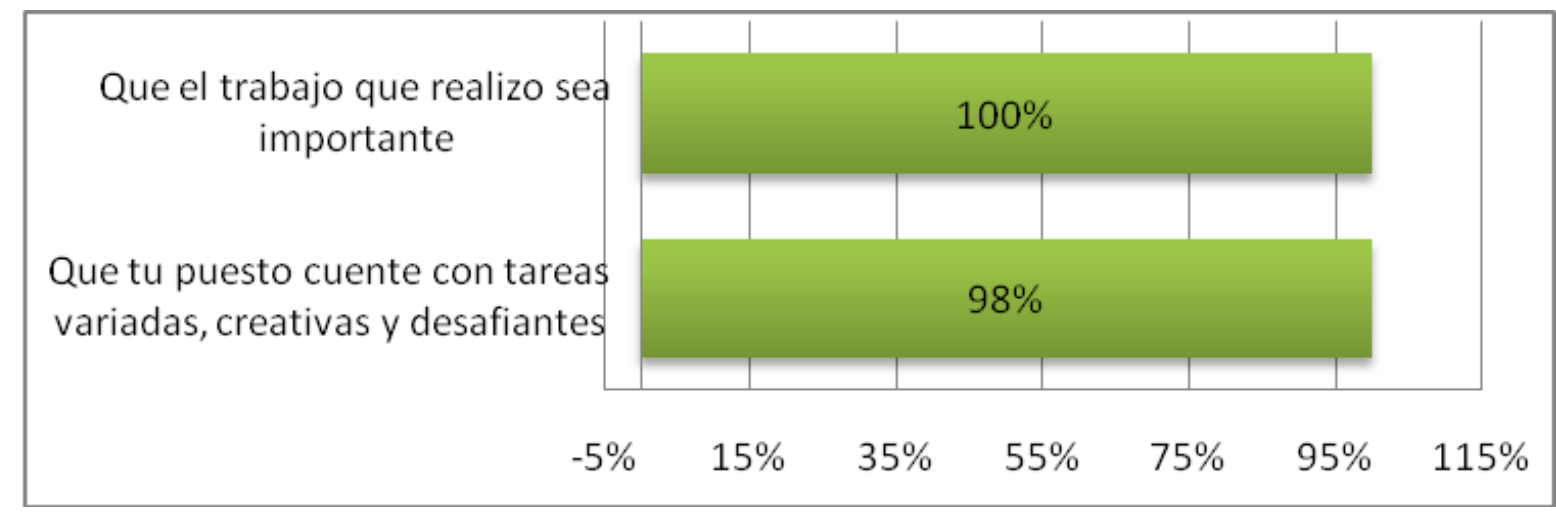


Las siguientes situaciones son también generadoras de satisfacción como se observan en el gráfico con un $95 \%$ de frecuencia.

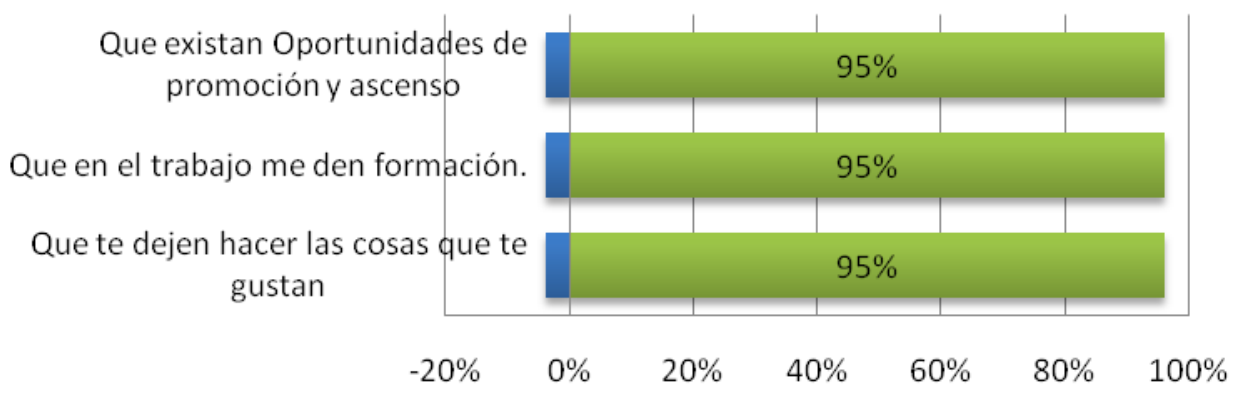

Se observa que a diferencia del análisis anterior (variables motivacionales), este cuadro muestra un panorama no tan marcado, respecto a la capacidad de que las situaciones planteadas en la encuesta sean generadoras o no de Satisfacción ya que se observan frecuencias altas.

Entre las variables con las mayores frecuencias de $88 \%$ a $80 \%$ se hallan tres situaciones posibles de generar más satisfacción que otras, entre ellas "las Relaciones con tus compañeros de trabajo", "El trato que recibo de mi jefe"; "Recibir apoyo del jefe"; de mayor a menor frecuencia.

Es importante destacar que la variable "El sueldo acorde con el trabajo que realizo" no fue la de mayor frecuencia, solo un $79 \%$ de trabajadores cree que un sueldo acorde lo mantendrá satisfecho.

Si se comparan ambas tablas se puede notar una aumento de la frecuencia de respuesta respecto a cómo las variables higiénicas son capaces de generar insatisfacción. 


\begin{tabular}{|c|c|c|c|c|c|c|}
\hline ANALISIS DE FRECUENCIAS Y PORCENTAJES DE & \multicolumn{3}{|c|}{ Frecuencia } & \multicolumn{3}{|c|}{ Porcentaje } \\
\hline Escala de valoración & $5-6-7$ & 4 & $1-2-3$ & $5-6-7$ & 4 & $1-2-3$ \\
\hline PREGUNTAS Y FACTORES HIGIENICOS & 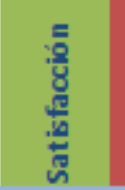 & 递 & 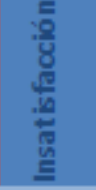 & 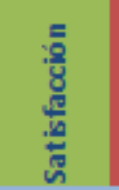 & 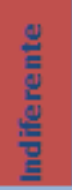 & 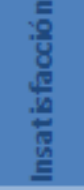 \\
\hline Supervisión & \multicolumn{3}{|c|}{ Frecuencia } & \multicolumn{3}{|c|}{ Porcentaje } \\
\hline Recibir el apoyo de tu jefe. & 83 & 16 & 5 & $80 \%$ & $15 \%$ & $5 \%$ \\
\hline Que tu jefe tenga una formación técnica acorde al puesto. & 80 & 12 & 12 & $77 \%$ & $12 \%$ & $12 \%$ \\
\hline La forma en la que tu jefe supervisa, organiza y dirige el trabajo. & 78 & 15 & 11 & $75 \%$ & $14 \%$ & $11 \%$ \\
\hline Políticas Generales de la Organización & \multicolumn{3}{|c|}{ Frecuencia } & \multicolumn{3}{|c|}{ Porcentaje } \\
\hline El cumplimiento del convenio y leyes laborales & 59 & 32 & 13 & $57 \%$ & $31 \%$ & $13 \%$ \\
\hline La organización de turnos horarios de trabajo & 62 & 28 & 14 & $60 \%$ & $27 \%$ & $13 \%$ \\
\hline Las normas y políticas generales de la empresa & 60 & 11 & 33 & $58 \%$ & $11 \%$ & $32 \%$ \\
\hline Remuneración & \multicolumn{3}{|c|}{ Frecuencia } & \multicolumn{3}{|c|}{ Porcentaje } \\
\hline Que el sueldo sea acorde al trabajo que realizas. & 82 & 0 & 22 & $79 \%$ & $0 \%$ & $21 \%$ \\
\hline Que el sueldo básico sea el del convenio. & 33 & 37 & 34 & $32 \%$ & $36 \%$ & $33 \%$ \\
\hline El dinero que recibo como premios e incentivos. & 75 & 15 & 14 & $72 \%$ & $14 \%$ & $13 \%$ \\
\hline Relaciones Humanas & \multicolumn{3}{|c|}{ Frecuencia } & \multicolumn{3}{|c|}{ Porcentaje } \\
\hline El Trato que recibis de tu jefe & 90 & 1 & 13 & $87 \%$ & $1 \%$ & $13 \%$ \\
\hline Las relaciones con tus compañeros de trabajo & 92 & 3 & 9 & $88 \%$ & $3 \%$ & $9 \%$ \\
\hline Que en tu empresa los traten con igualdad y justicia. & 80 & 15 & 9 & $77 \%$ & $14 \%$ & $9 \%$ \\
\hline Condiciones de trabajo & \multicolumn{3}{|c|}{ Frecuencia } & \multicolumn{3}{|c|}{ Porcentaje } \\
\hline La Limpieza, higiene y salubridad del lugar de trabajo & 64 & 11 & 29 & $62 \%$ & $11 \%$ & $28 \%$ \\
\hline Los recursos materiales que tengo para hacer mi trabajo & 66 & 11 & 27 & $63 \%$ & $11 \%$ & $26 \%$ \\
\hline Con la comodidad del ambiente de trabajo & 70 & & 34 & $67 \%$ & $0 \%$ & $33 \%$ \\
\hline
\end{tabular}

El siguiente gráfico muestra las frecuencias de ambos tipos de factores, en el mismo se puede observar el rol predominante de los factores motivacionales del puesto de trabajo, para la mayoría de los trabajadores los factores motivacionales mostraron ser causas más poderosas de satisfacción/ insatisfacción que los factores Higiénicos.

Este gráfico muestra los porcentajes de veces que fue elegido cada factor como causante de satisfacción o insatisfacción.

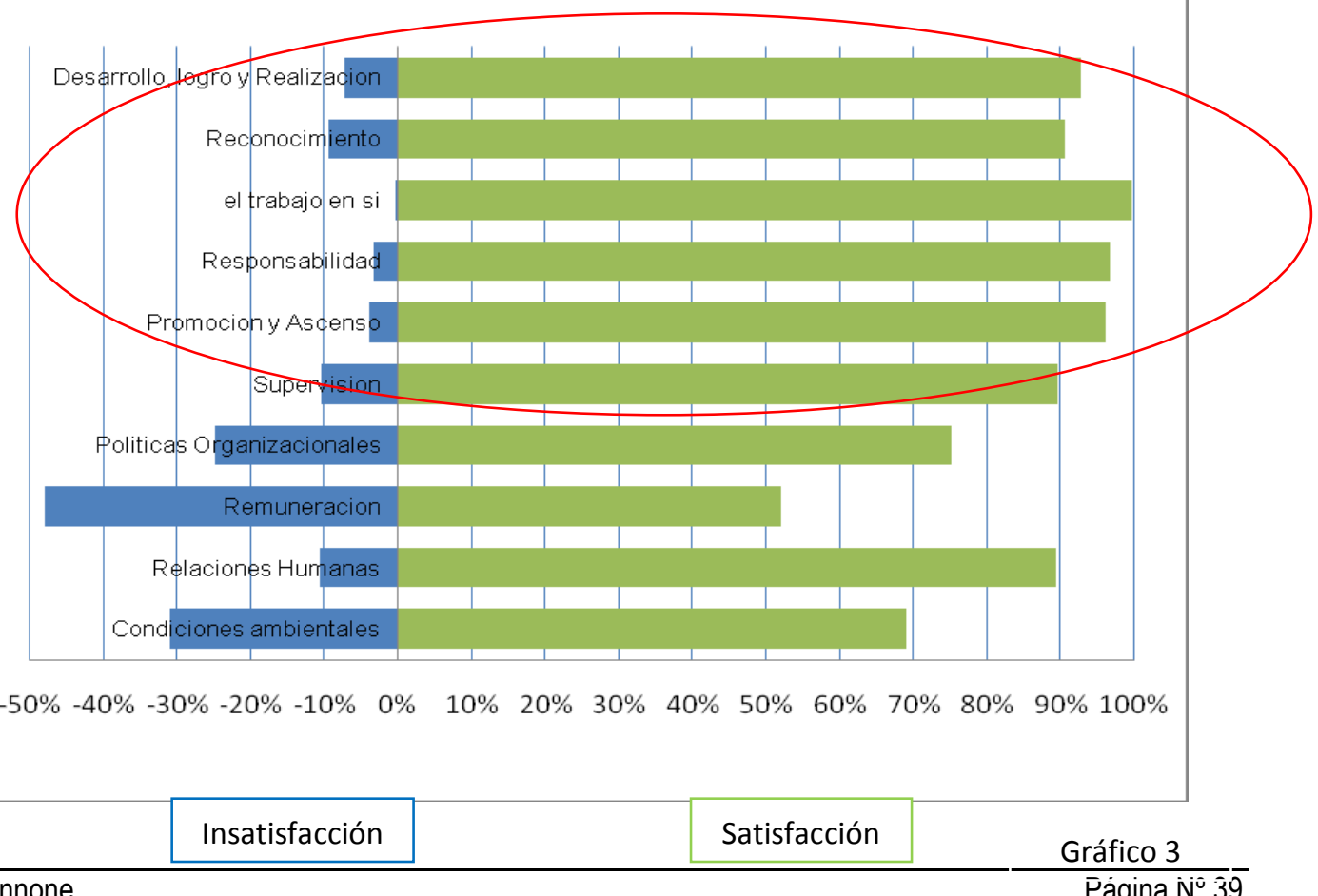


Mediante la pregunta ¿Cuán satisfecho esta con su puesto actual? Se trato de analizar el grado de satisfacción actual con su puesto de trabajo, las respuestas fueron:

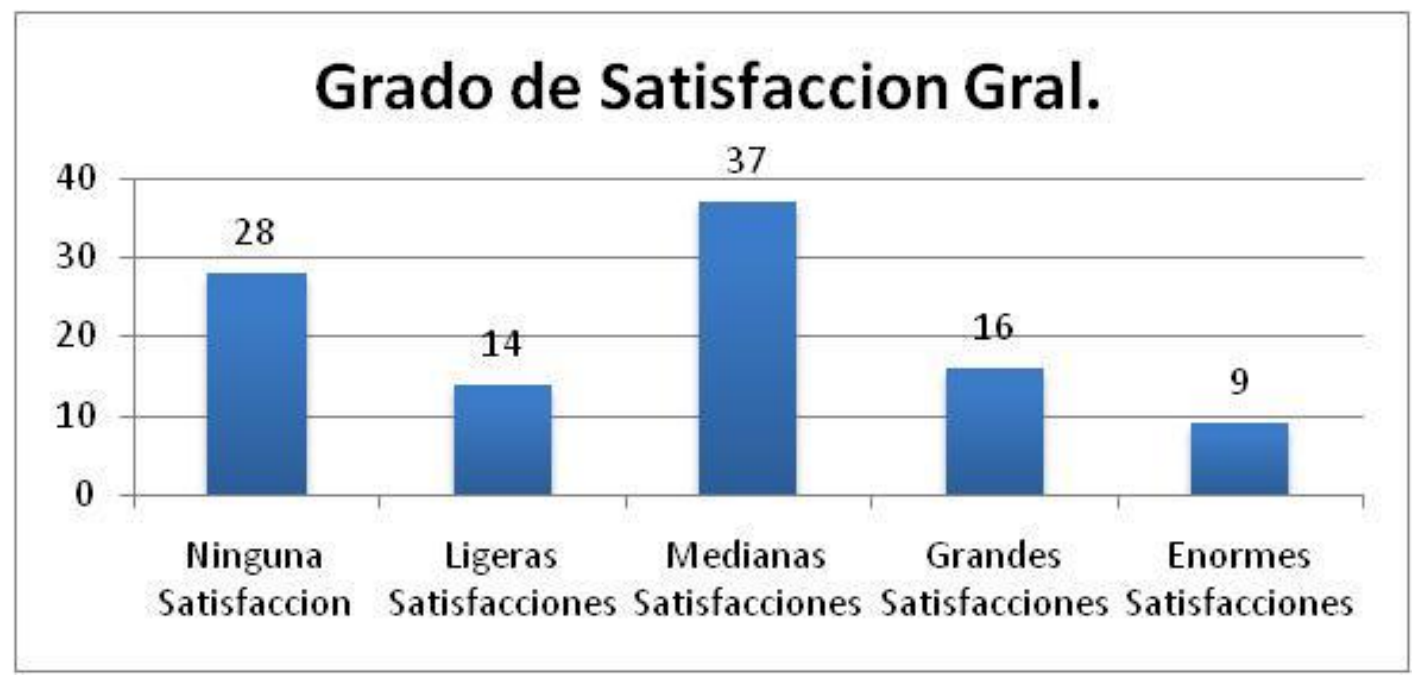

En el gráfico se observa que un $37 \%$ de los trabajadores se encuentran medianamente satisfechos con su puesto actual, mientras que un $28 \%$ confeso, "ninguna satisfacción", en general las respuestas fueron bastantes dispersas. 


\section{Análisis de regresión}

Primero se determinó la tabla de correlaciones entre todas las variables. Luego se armó una tabla de correlaciones entre todas las variables organizadas por columnas de a pares y ordenada por correlación de mayor a menor.

Se trató de realizar un análisis de regresión con las 27 variables (independientes) para explicar la "Satisfacción General" (Variable dependiente), pero dado que el MS Excel solo permite trabajar con un máximo de 16 variables independientes, se tomaron aquellas de mayor correlación $\left(\mathrm{x}_{\mathrm{t}} ; \mathrm{y}\right)$ en valor absoluto.

\section{Las mismas son:}

\section{$N^{\circ}$ VARIABLES CON MAYOR CORRELACION}

\begin{tabular}{|r|r|l}
\hline 1 & Que el trabajo que realizo sea importante & 0.474486659 \\
\hline 2 & Que el sueldo básico sea el del convenio & 0.429361855 \\
\hline 3 & Que el sueldo sea acorde al trabajo que realizas & 0.427972036 \\
\hline 4 & Los recursos materiales que tengo para hacer mi trabajo & 0.382797126 \\
\hline 5 & Que existan Oportunidades de promoción y ascenso & 0.380638634 \\
\hline 6 & Recibir el apoyo de tu jefe & 0.3785217 \\
\hline 7 & Que en el trabajo me den formación & 0.353064095 \\
\hline 8 & Que tengas participación en las decisiones de mi depto & 0.32328776 \\
\hline 9 & Que tu jefe te reconozca los trabajos bien hechos & 0.320380893 \\
\hline 10 & Que en tu empresa los traten con igualdad y justicia & 0.320100527 \\
\hline 11 & Que tu trabajo tenga cierta responsabilidad & 0.27488792 \\
\hline 12 & Que tu jefe preste atención a la calidad de tu trabajo & 0.184448291 \\
\hline 13 & La organización de turnos horarios de trabajo & 0.170950358 \\
\hline 14 & Con la comodidad del ambiente de trabajo & 0.164421323 \\
\hline 15 & Las normas y políticas generales de la empresa & 0.139684944 \\
\hline 16 & Tener la posibilidad de que en el trabajo, te dejen hacer las cosas en las que mas te destacas & 0.12815356 \\
\hline & M & \\
\hline
\end{tabular}

NOTA: (Variables con mayor coeficiente de correlación en valor absoluto )

Con estos datos se generó una regresión cuyos resultados pueden observarse en la siguiente tabla. 


\section{Tabla de Regresion 1}

\begin{tabular}{lr}
\hline \multicolumn{2}{c}{ Estadisticas de la regresión } \\
\hline Coeficiente de correlación múltiple & 0.99359446 \\
Coeficiente de determinación R^2 & 0.98722995 \\
$\mathrm{R}^{\wedge} 2$ ajustado & 0.9736896 \\
Error típico & 0.5422189 \\
Observaciones & 104 \\
\hline
\end{tabular}

\section{ANÁLISIS DE VARIANZA}

\begin{tabular}{lrrrrr}
\hline & Grados de libertna de cuadradio de los cua & $F$ & alor crítico de \\
\hline Regresión & 16 & 2000.12788 & 125.007993 & 425.195325 & $2.5129 \mathrm{E}-75$ \\
Residuos & 88 & 25.8721174 & 0.29400133 & & \\
Total & 104 & 2026 & & & \\
\hline
\end{tabular}

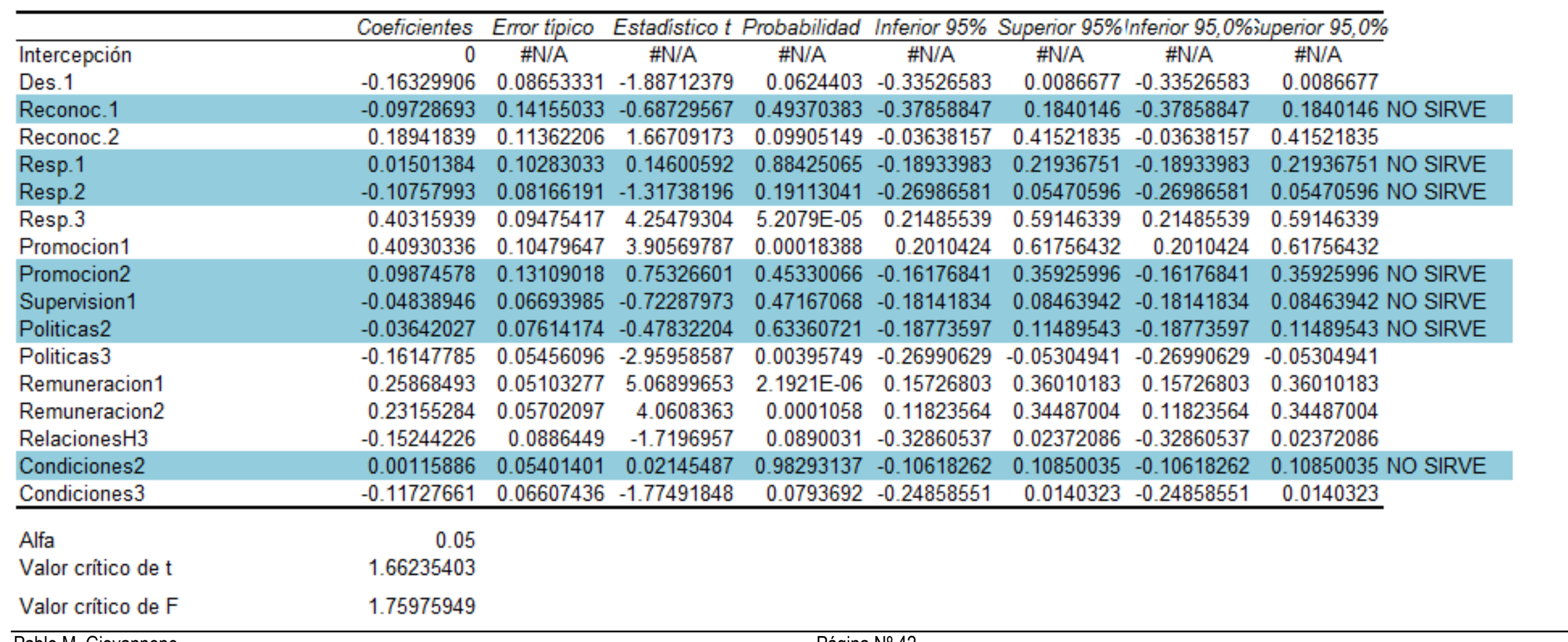

Pablo M. Giovannone 
En la misma se observó un alto coeficiente de correlación y $R$ cuadrado y un $F$ estadístico que indica que la ecuación de regresión es útil en la predicción de valores de la variable dependiente.

Al realizar el test de la t de Student, algunas variables motivacionales e higiénicas no mostraron ser tan significativas en la estimación de la satisfacción general. Indicadas con celeste en la tabla de regresión 1.

Se generó una nueva base de datos con las variables independientes que superaron el test t de Student. Se realizó una nueva regresión con estas variables cuyos resultados pueden observarse en la tabla de Regresión 2.

Otra vez se aprecia un muy alto coeficiente de correlación y $\mathrm{R}$ cuadrado y que el $\mathrm{F}$ estadístico indica que la ecuación de regresión es útil en la predicción de los valores de la variable dependiente. Pero el problema surge nuevamente, según la t de Student, las variables independientes coloreadas no son importantes en la estimación del valor de la variable dependiente. 


\section{Tabla de Regresión 2}

\begin{tabular}{lr}
\hline \multicolumn{2}{c}{ Estadísticas de la regresión } \\
\hline Coeficiente de correlación múltiple & 0.99316971 \\
Coeficiente de determinación $\mathrm{R}^{\wedge} 2$ & 0.98638608 \\
$\mathrm{R}^{\wedge} 2$ ajustado & 0.97471333 \\
Error típico & 0.5388272 \\
Observaciones & 104 \\
\hline
\end{tabular}

ANÁLISIS DE VARIANZA

\begin{tabular}{|c|c|c|c|c|}
\hline & Grados de libertna de cuadrac & lo de los cua & $F$ & alor crítico de $P$ \\
\hline Regresión & $\begin{array}{rll}9 & 1998.4182\end{array}$ & 222.046466 & 764.79465 & $8.3451 \mathrm{E}-84$ \\
\hline Residuos & 27.5818016 & 0.29033475 & & \\
\hline Total & 2026 & & & \\
\hline
\end{tabular}

\begin{tabular}{|c|c|c|c|c|c|c|c|c|}
\hline & Coeficientes & Error tipico & Estadistico $t$ & Probabilidad & Inferior $95 \%$ & Superior $95 \% !$ & Inferior $95,0 \%$ & uperior $95,0 \%$ \\
\hline Intercepción & 0 & \#N/A & \#N/A & \#N/A & \#N/A & \#N/A & \#N/A & \#N/A \\
\hline Des.1 & -0.22696854 & 0.07400537 & -3.06691978 & 0.00281715 & -0.37388778 & -0.0800493 & -0.37388778 & -0.0800493 \\
\hline Reconoc. 2 & 0.1056766 & 0.05104656 & 2.07020022 & 0.04114707 & 0.00433637 & 0.20701684 & 0.00433637 & 0.20701684 \\
\hline Resp.3 & 0.43408074 & 0.05370132 & 8.08324201 & $2.0096 \mathrm{E}-12$ & 0.32747015 & 0.54069133 & 0.32747015 & 0.54069133 \\
\hline Promocion1 & 0.37087307 & 0.06229259 & 5.95372707 & 4.3889E-08 & 0.24720665 & 0.49453948 & 0.24720665 & 0.49453948 \\
\hline Politicas3 & -0.17202104 & 0.04235093 & -4.06180034 & 0.00010016 & -0.25609827 & -0.08794381 & -0.25609827 & -0.08794381 \\
\hline Remuneracion 1 & 0.22986886 & 0.04547715 & 5.05460085 & $2.0898 \mathrm{E}-06$ & 0.1395853 & 0.32015242 & 0.1395853 & 0.32015242 \\
\hline Remuneracion2 & 0.22112733 & 0.0446519 & 4.95224853 & $3.1811 \mathrm{E}-06$ & 0.13248209 & 0.30977257 & 0.13248209 & 0.30977257 \\
\hline RelacionesH3 & -0.17864648 & 0.0590263 & -3.02655754 & 0.00318321 & -0.29582849 & -0.06146447 & -0.29582849 & -0.06146447 \\
\hline Condiciones 3 & -0.04848137 & 0.0495556 & -0.97832268 & 0.33039955 & -0.14686168 & 0.04989894 & -0.14686168 & 0.04989894 NO SIRVE \\
\hline Alfa & 0.05 & & & & & & & \\
\hline Valor crítico de $t$ & 1.66105182 & & & & & & & \\
\hline Valor crítico de F & 1.97992324 & & & & & & & \\
\hline
\end{tabular}


Se generó una nueva base de datos con las variable independientes que superaron el test t de Student. Se realizó una nueva regresión con estas variables cuyos resultados pueden observarse en la tabla de Regresión 3

Finalmente al realizar el test $\mathrm{t}$ de Student, las variables independientes correlacionadas son relevantes en la estimación de la satisfacción.

Las 8 variables motivacionales e Higiénicas que explican muy precisamente la variable Satisfacción General son:

\section{Variables con mayor correlación y explicativas de la "Satisfacción}

Tener la posibilidad de hacer lo que te gusta

\section{Que el jefe preste atención a la calidad de tu trabajo}

Que el trabajo que realizo sea importante

Que en el trabajo me den formación

Las normas y políticas generales de la empresa

\section{Que el sueldo sea acorde al trabajo que realizo}

\section{Que el sueldo básico sea el del convenio}

\section{Que lo traten con igualdad y justicia}

La aplicación de la ecuación de regresión de las ocho variables para determinar la satisfacción general, generan una gráfica muy similar a los datos reales de satisfacción general.

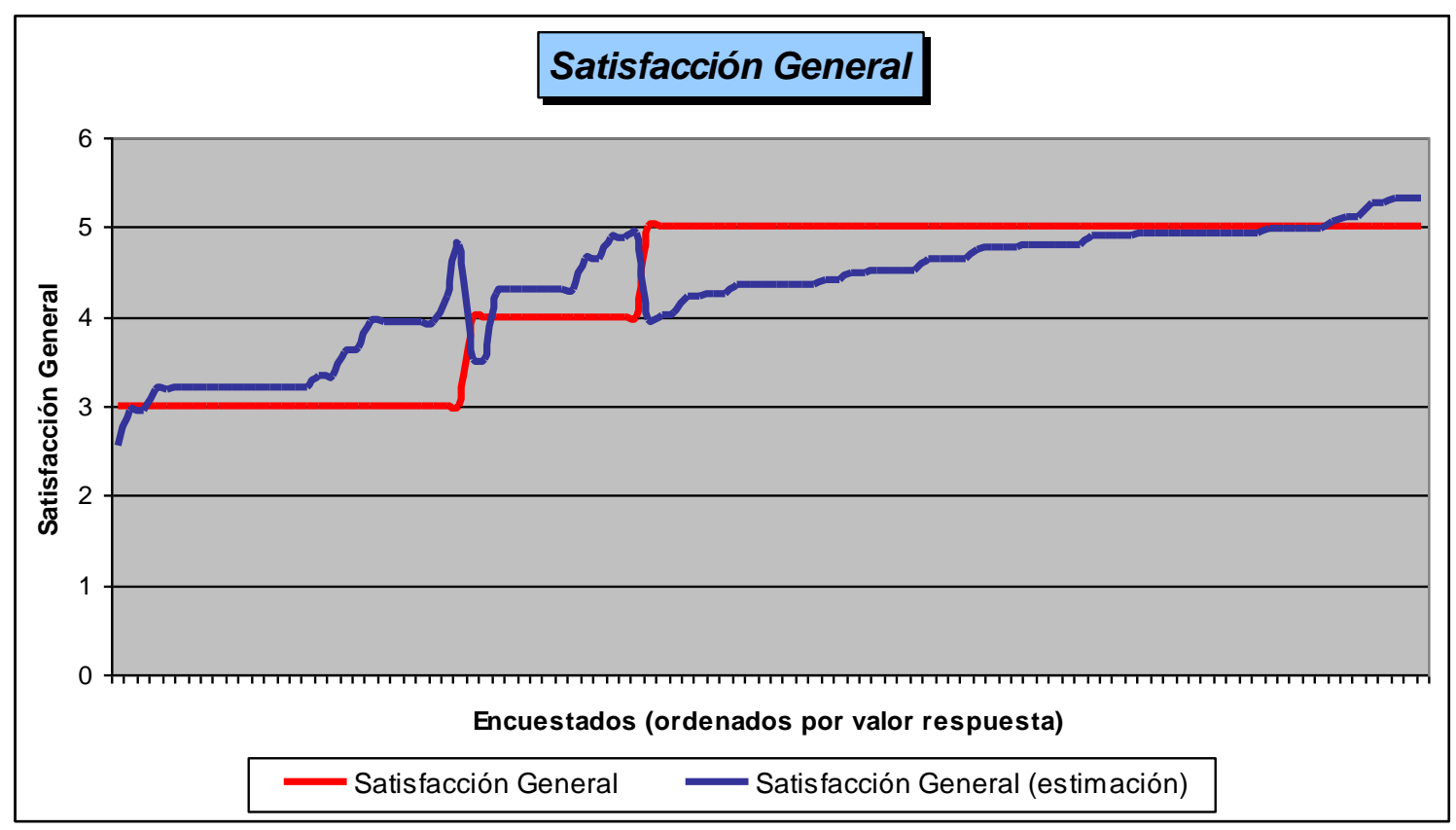




\section{Tabla de Regresión 3}

\begin{tabular}{lr}
\hline \multicolumn{2}{c}{ Estadisticas de la regresión } \\
\hline Coeficiente de correlación múltiple & 0.99310066 \\
Coeficiente de determinación $\mathrm{R}^{\wedge} 2$ & 0.98624892 \\
$\mathrm{R}^{\wedge} 2$ ajustado & 0.97482957 \\
Error típico & 0.53870684 \\
Observaciones & 104 \\
\hline
\end{tabular}

\section{ANÁLISIS DE VARIANZA}

\begin{tabular}{lrrrrr}
\hline & Grados de libertna de cuadracdio de los cua & $F$ & alor critico de $F$ \\
\hline Regresión & 8 & 1998.14031 & 249.767539 & 860.658812 & $4.4253 \mathrm{E}-85$ \\
Residuos & 96 & 27.8596854 & 0.29020506 & & \\
Total & 104 & 2026 & & & \\
\hline
\end{tabular}

\begin{tabular}{|c|c|c|c|c|c|c|c|c|}
\hline & Coeficientes & Error tipico & Estadistico $t$ & Probabilidad & Inferior $95 \%$ & Superior $95 \%$ & nferior $95,0 \%$ & uperior $95,0 \%$ \\
\hline Intercepción & 0 & \#N/A & \#N/A & \#N/A & \#N/A & \#N/A & \#N/A & \#N/A \\
\hline Tener la posibilidad de hacer lo que te gusta & -0.25127017 & 0.06969644 & -3.60520793 & 0.00049693 & -0.38961651 & -0.11292383 & -0.38961651 & -0.11292383 \\
\hline Que el jefe preste atencion a la calidad de tu trabajo & 0.11685251 & 0.04974081 & 2.34922816 & 0.02086154 & 0.01811779 & 0.21558724 & 0.01811779 & 0.21558724 \\
\hline Que el trabajo que realizo sea importante & 0.43063504 & 0.05357372 & 8.0381764 & $2.3588 \mathrm{E}-12$ & 0.32429204 & 0.53697804 & 0.32429204 & 0.53697804 \\
\hline Que en el trabajo me den formacion & 0.37169561 & 0.062273 & 5.96880858 & 4.0063E-08 & 0.24808469 & 0.49530654 & 0.24808469 & 0.49530654 \\
\hline Las normas y politicas grales de la empresa & -0.19299717 & 0.03651429 & -5.28552494 & 7.8432E-07 & -0.26547745 & -0.12051688 & -0.26547745 & -0.12051688 \\
\hline Que el sueldo sea acorde al trabajo que realizo & 0.22281638 & 0.04489215 & 4.96337106 & 2.9997E-06 & 0.13370618 & 0.31192659 & 0.13370618 & 0.31192659 \\
\hline Que el sueldo basico sea el del convenio & 0.22501143 & 0.04446512 & 5.0604031 & 2.0117E-06 & 0.13674886 & 0.31327399 & 0.13674886 & 0.31327399 \\
\hline Que lo traten con igualdad y justicia & -0.18622833 & 0.05850226 & -3.18326751 & 0.00196317 & -0.30235439 & -0.07010227 & -0.30235439 & -0.07010227 \\
\hline Alfa & 0.05 & & & & & & & \\
\hline Valor crítico de t & 1.66088144 & & & & & & & \\
\hline Valor crítico de F & 2.03631902 & & & & & & & \\
\hline
\end{tabular}




\section{Conclusiones}

Los profesionales trabajadores presentaron niveles altos de satisfacción en la mayoría de los factores motivacionales.

Los resultados de la investigación de campo señalan que: entre los factores motivacionales que los trabajadores de la muestra consideran más importantes a la hora de sentirse motivados se encuentra; que el trabajo que realiza sea importante como también que el puesto cuente con tareas variadas, desafiantes y creativas.

Las siguientes situaciones que los trabajadores consideran importantes a la hora de estar satisfechos con su trabajo, con un $95 \%$ de frecuencia son:

- Que existan oportunidades de promoción y ascenso.

- Que en el trabajo me den formación

- Que te dejen hacer las cosas que te gusta

Entre las restantes situaciones que los trabajadores consideraron importantes para sentirse motivados, con frecuencias superiores a $90 \%$ se encontró que, tener la libertad para realizar y organizar el trabajo sus manera; que el jefe reconozca aquellos trabajos bien hechos, el tipo de tareas y actividades que tiene en el puesto, como así también que las mismas tengan cierto grado de responsabilidad.

Es importante destacar que todas las situaciones con frecuencias entre $90 \%$ y $100 \%$ fueron aquellas que trataron de medir los factores motivacionales (generadores de satisfacción), por lo que se puede decir que las mayores frecuencias las tuvieron los factores:

- Responsabilidad

- El trabajo en sí

- Desarrollo, logro y responsabilidad

- Promoción y ascenso

- Reconocimiento

También se observa que las situaciones "Libertad para organizar y realizar el trabajo"; "Que el puesto cuente con tareas variadas, creativas y desafiantes" y que sean a su vez "importantes" no fueron catalogadas por trabajador alguno, como capaces de generar insatisfacción,

En general se observaron frecuencias superiores al $83 \%$ como generadoras de satisfacción en todas las situaciones que medían los factores motivacionales, lo que permite afirmar que estos factores que Herzberg considero importantes a la hora de motivar, siguen estando vigentes en la actualidad.

Mientras que los factores higiénicos que más insatisfacción causan y que según Herzberg si están presentes y son óptimos, como por ejemplo una buena Política organizacional, sólo evitan la insatisfacción de los empleados, pues no consiguen elevar consistentemente la satisfacción, y cuando la elevan, no logran sostenerla por mucho tiempo, pero, cuando los factores higiénicos son pésimos o precarios, provocan la insatisfacción de los empleados se ha encontrado: 
En primer término

- Que el sueldo básico sea el del convenio: $33 \%$

- La comodidad del ambiente de trabajo: $33 \%$

Como también

- Las normas y políticas generales de la empresa: $32 \%$

- La limpieza, higiene y salubridad del trabajo: $28 \%$

- Que el sueldo sea acorde con el trabajo que realizo: $40 \%$

Estas situaciones se incluyen en los factores higiénicos que describe Herzberg "Políticas Organizacionales"; "Remuneración" y "Condiciones de trabajo", corroborando su teoría.

Existe abundante información como así también numerosos gerentes, que señalan al dinero como principal elemento motivador, los resultados de esta investigación muestran a la remuneración como un factor con capacidad para genera estado de satisfacción; aunque su frecuencia acumulada no supere a los factores motivadores.

Si se analizan las respuestas que se refieren a la medición de este factor se encuentra que aproximadamente un $75 \%$ de los encuestados consideran que perciben "un sueldo acorde con las tareas que realiza" y que los "premios e incentivos" que reciben, producen un estado de satisfacción.

Mientras que si el sueldo que cobra es el que corresponde según el sindicato, ni más ni menos, esta situación genera una gran insatisfacción.

Esto se debería a que el trabajador razona que si le pagan más que su sueldo básico, es porque se lo considera un buen empleado; porque aporta con sus tareas a una labor clave de la empresa, porque sus tareas tienen responsabilidad, etc., por lo tanto su excedente de remuneración se debe a los factores motivacionales, según Herzberg.

Es importante recordar que si le aumentan el sueldo a un trabajador, esto funcionará como motivador por un corto período, y a medida que pase el tiempo se acostumbrará a ese sueldo y dejará de ser un motivador.

Esto lleva a la reflexión de que a la hora de poner en marcha herramientas de motivación, basadas solamente en factores económicos, se puede correr el riesgo, si no se las acompaña con factores motivadores, de caer en el corto plazo en la desmotivación.

La investigación permitió medir el grado de satisfacción e insatisfacción de los trabajadores respecto de su trabajo actual.

Cuando se preguntó cuan satisfecho está con su puesto actual, las repuestas fueron: 
Un $37 \%$ de los trabajadores se encuentran medianamente satisfechos con su puesto actual, mientras que un $28 \%$ expresó, "ninguna satisfacción".

Este resultado disperso, puede explicarse debido a que a la mayoría de los profesionales no les gusta contar frente a los demás que no está conforme con su puesto actual, ya que esa respuesta daría una mala imagen de él como profesional, daría a pensar "No puedes conseguir algo mejor", "Estas fuera de carrera", "no te da para otro puesto mejor" etc.

El gráfico 3 de la sección «análisis de resultados», confirma el rol predominante de los factores motivacionales del puesto de trabajo. Para la mayoría de los trabajadores los factores motivacionales mostraron ser causas más poderosas de satisfacción / insatisfacción que los factores Higiénicos.

Estas conclusiones son similares a las halladas por Herzberg en su teoría de los factores. Estos tienden a ser más poderosos que los factores higiénicos tanto causando sentimientos de satisfacción en el trabajo como condicionando experiencias de insatisfacción.

No existe un orden objetivo de los factores que inciden en la motivación laboral de los trabajadores, o al menos no se ha encontrado un patrón que lo muestre; la jerarquía de los factores motivacionales depende del puesto que cada trabajador ocupe.

Se puede afirmar que siguen estando vigentes estos factores a la hora de motivar

Cabe aclarar que se deja de lado en este gráfico la profundización de aquellos motivos que fueron indicados como indiferentes, debido a que el trabajo se centra en la satisfacción e insatisfacción.

También es posible considerar que frente a la pregunta, aquel trabajador que no tenía claro que le generaba la situación planteada, marcaba la respuesta como indiferente.

"Estoy convencido que la inmensa mayoría de las personas desean trabajar bien y ser productivos, lógicamente lo harán si se les ofrece un ambiente adecuado, dentro del marco de la consideración y el respeto; así como reconociendo su esfuerzo y resultados, alertándolos también sobre sus errores".

Finalmente, los resultados del análisis de correlaciones y regresiones permiten aseverar que los factores motivadores: "desarrollo, logro y realización"; "reconocimiento"; "responsabilidad" y "promoción y ascenso" deben estar presentes a la hora de estimar la satisfacción laboral de los trabajadores del gran La Plata. Junto con los factores higiénicos "Políticas generales de la empresa"; "remuneración" y "relaciones con sus compañeros". Resultados que se acercan a la teoría de Herzberg.

Al tratar de realizar una interpretación de estos resultados, se puede afirmar que casi todos los factores de desarrollo o motivadores intrínsecos al trabajo así como los factores de higiene o extrínsecos al trabajo, están presentes en la percepción (y valoración) de los trabajadores del gran La Plata. 


\section{Bibliografía}

\section{Trabajos}

- CANTERA LÓPEZ, Francisco Javier. 2004. "Evaluación De La Satisfacción Laboral: Métodos Directos E Indirectos" In: Publicaciones del Ministerio de trabajo y asuntos sociales de España.

- CANTERA LÓPEZ, Francisco Javier. 2004. "Satisfacción Laboral: Encuesta De Evaluación" In: Publicaciones del Ministerio de trabajo y asuntos sociales de España.

- CANTERA LÓPEZ, Francisco Javier. 2004. "Satisfacción Laboral: Escala General De Satisfacción" In: Publicaciones del Ministerio de trabajo y asuntos sociales de España.

- LOPEZ, Julio. 2005. "Motivación laboral y gestión de recursos humanos en la teoría de Frederick Herzberg" In: Gestión en el Tercer Milenio, Rev. De Investigación de la Fac. de Ciencias Administrativas, Vol. 8, № 15.

- RAMOS, Martina; LÓPEZ, María E. 1999. "Satisfacción laboral del personal de salud del Instituto Mexicano del Seguro Social”. México.

- WALDINA, Elida; TORRES Mejía. 2006. "Escala De Satisfacción Laboral En El Personal De "Viveros Tropicales S.A". Honduras. www.monografias.com

\section{Artículos y Revistas}

- LEON, Federico R; SEPULVEDA, María P. 1989. "Satisfacciones E Insatisfacciones Herzbergianas En El Trabajo”. In: Revista Latinoamericana de Psicología. Vol.11 № 1 pp. 93 $-113$

- LEON, Federico R; PEJERREY Gerardo P. 1980. "Factores Considerados Por Empleados De Oficina Y Por Trabajadores Mensuales Al Ofrecerles Un Puesto". In: Revista Latinoamericana de Psicología. Vol.12 № 2 pp. 253 - 280.

- MANZO PINTO, Juan. 2002. "El Legado De Frederick Irving Herzberg". In: Revista Universidad EAFIT oㅜ 128.

- VENNUCCI, María. 2009. "La razón que lleva a querer cambiar de trabajo" In: INFOBAE. 29 de enero.

\section{Libros Generales}

- CHIAVEnAto, I. 2002. "Administración de Recursos Humanos". México, Quinta edición. McGraw-Hill.

- GENESCA, Enric.1977. "Motivación y enriquecimiento del trabajo". España, Hispano Europea

- JIMÉNEZ, Alicia; BUENO BLANCO, José Luis.2003. “¿Qué motiva a sus colaboradores?”. España, Ed. Fundación Confemetal.

- LÓPEZ, González Luis. 2001. "Satisfacción y motivación en el trabajo". España, Díaz de Santos

- ROB, Goffee y GARETH, Jones. 2004. "Dirigir Personas en la empresa”. Argentina, Planeta.

- STEVENSON, Nancy.2000. "La motivación del personal de su empresa". España, Pearson Educación, S.A. 


\section{Libros Y Papers de Herzberg}

- HERZBERG, Frederick. 1968. "Una Vez Más: ¿Cómo Motiva Usted A Sus Empleados?". España, Harvard Business Review, pp. 13-22. Traducción al español: José Luis Pariente F.

- HERZBERG, Frederick. "Work And The Nature Of Man". 1996. Cleveland, World Publishing Company

\section{Cuestionarios y Metodologías}

- AREllano, Cira Rita; GAllegos, Rómulo. "Modelo De Motivacion Para Reforzar El Desempeño Y El Compromiso De Los Gerentes Del El Instituto De Mejoramiento Profesional Del Magisterio Universidad Pedagogica Experimental Libertador". In: http://biblioteca.universia.net/index.htm

- BETZ, Ellen L. "Dos Análisis De La Teoría De Maslow Sobre La Satisfacción De La Necesidad". In: http://www.fun-humanismo-ciencia.es/felicidad/maslow.htm. Universidad de Minnesota.

- HERRERA, Francisco. 2001. "Factores de Motivación de Herzberg - cuestionario". In: http://www.rr-hh.com/inicio.asp

- J.L. Meliá y J.M. Peiró. 1998. "Cuestionario De Satisfacción Laboral S4/82". In: http://www.uv.es/seguridadlaboral.

- J.L. Meliá y J.M. Peiró. 1998. "Cuestionario De Satisfacción Laboral S20/23". In: http://www.uv.es/seguridadlaboral.

- J.L. Meliá y J.M. Peiró. 1999. "El Instrumento de medida: El Cuestionario De Satisfacción S10/12". In: http://www.uv.es/seguridadlaboral.

- J.L Meliá,.., Pradilla, J.F., Martí, N., Sancerni, M.D., Oliver, A., \& Tomás J.M. (1990). "Estructura factorial, fiabilidad y validez del Cuestionario de Satisfacción S21/26Un Instrumento con formato dicotómico orientado al trabajo profesional".In: Revista de Psicologia Universitas Tarraconensis, 12(1/2), 25-39.

- MARTIN, Antonio L.2004. "Una aproximación sociológica al estudio de la satisfacción en el trabajo en la provincia de Santander."In: Reis - Revista Española de Investigaciones Sociológicas - 13/81 pp. 65-100

- RAMELLA, Cristina. 1995. "Estudio de la satisfacción laboral y sus determinantes en los trabajos sanitarios de un área de Madrid". In: Rev. Especializada en Salud Publica -№ 6pp.487-497

- TORRES, Alejandro; MARTíNEZ, Carlos.2002. "Estudio del síndrome de «Burnout»en cirujanos pediatras españoles" In: Rev. Del Hospital Universitario «Virgen de las Nieves». Granada, Facultad de Psicología. Universidad de Granada. Vol. 15 n 2.

- HERNÁNDEZ Gómez Rodolfo, VELASCO DUBON Regina, JIMÉNEZ Sandra. 2000. "La motivación laboral de los empleados en el Hospital Nacional de Niños Dr. Carlos Sáenz Herrera". In: Rev. Cienc. adm. financ. segur. soc [revista en la Internet]. http://www.scielo.sa.cr/scielo.php?script=sci_arttext\&pid=S1409$12592000000100005 \& \operatorname{lng}=$ es.

- VALVERDE, Alvares. 2001. "La cultura y el clima organizacional como factores relevantes en la eficacia del instituto de oftalmología." In: Tesis UNMSM 


\section{Referencias y Anexos}

\section{Anexo 1: Encuesta de Satisfacción Laboral}

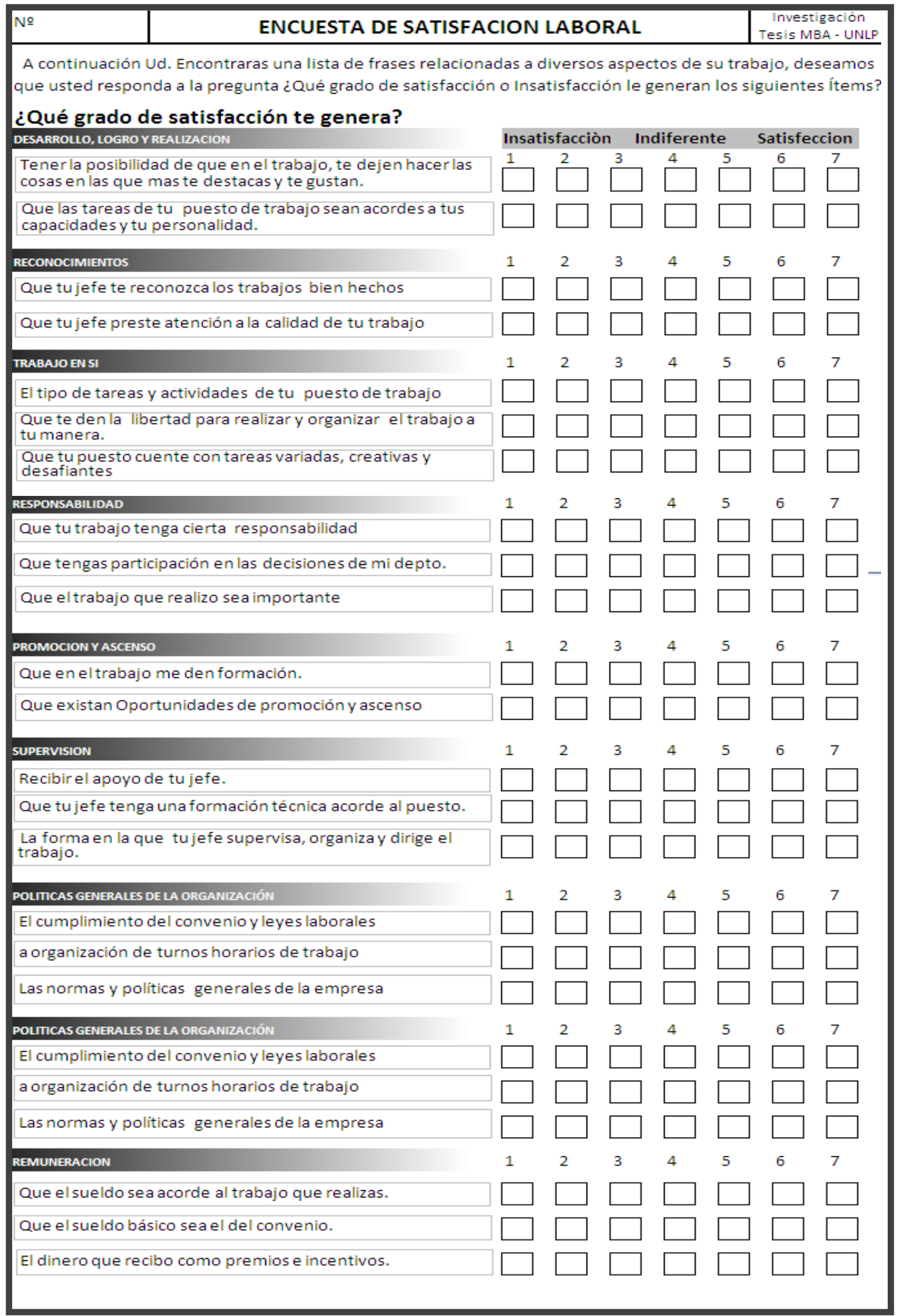




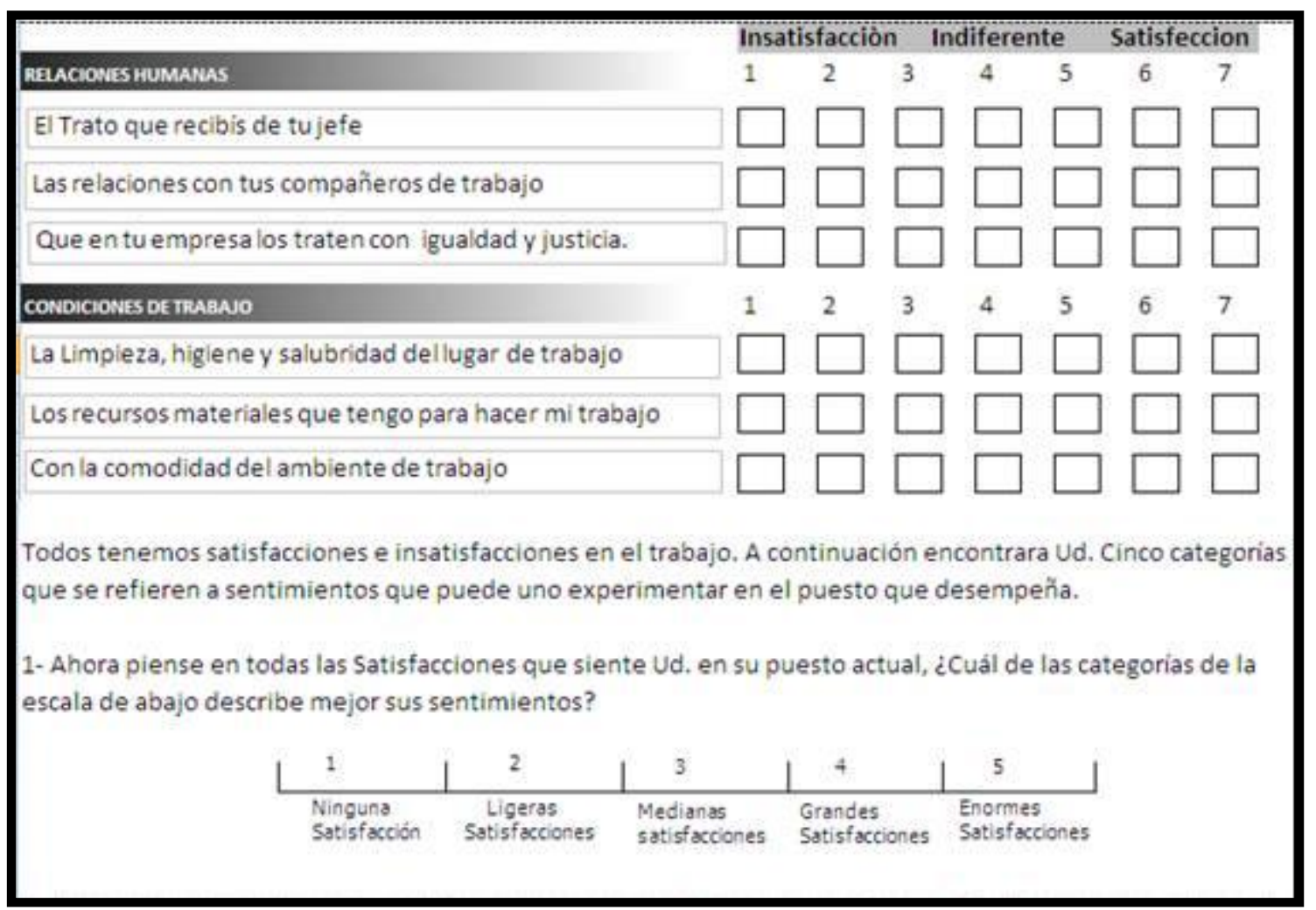




\section{Anexo 2: Gráfico original de los hallazgos de Herzberg}

Comparación de motivos de

Insatisfacción y Satisfacción laboral

(200 ingenieros y contables de Pittsburg, Herzberg 1967)

A través del\% de veces que se cita cada factor laboral, como causante de una u otra.

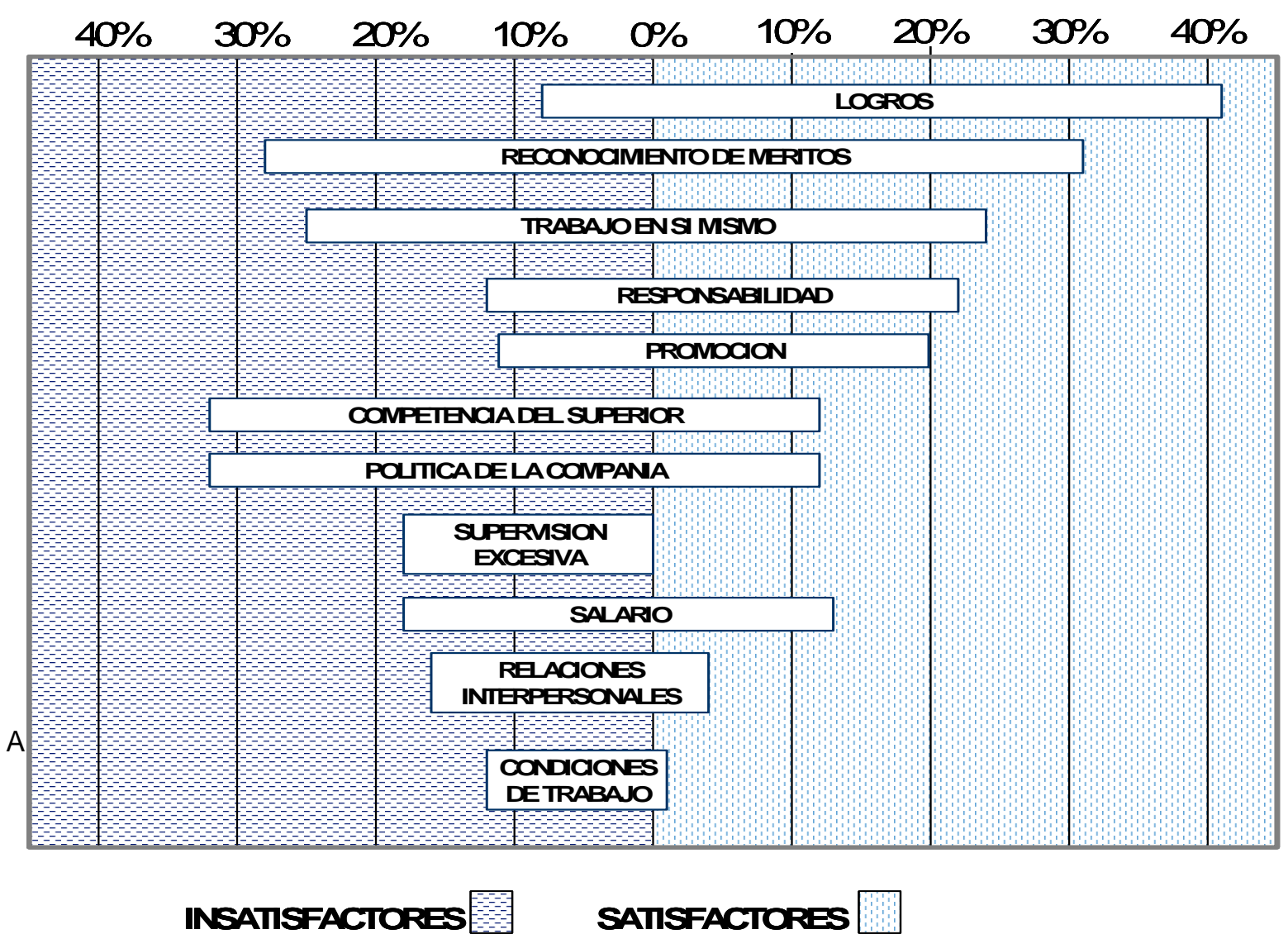

